\title{
Alguns aspectos da função endotelial em cirurgia cardíaca
}

\author{
Paulo Roberto B. ÉVORA *, Paul J. PEARSON **, Hartzell V. SCHAFF ***
}

ÉVORA, P.R.B.; PEARSON, P.J.; SCHAFF, H.V. - Alguns aspectos da função endotelial em cirurgia cardiaca. Rev. Bras. Cir. Cardiovasc., 8(3): 195-214, 1993.

RESUMO: Este estudo mostra alguns aspectos da função endotelial relacionados, diretamente, com a cirurgia cardiaca: 1) Após isquemia miocárdica global seguida de reperfusão, o endotélio coronariano perde a habilidade de expressar vasodilatação endotélio-dependente mediada por receptores, ao passo que o relaxamento endotélio-dependente mediado pelo cálcio ionóforo A23187 e a fosfolipasec C, que não dependem de estimulaçāo de receptores, encontra-se inalterada. O relaxamento produzido pelo fluorêto de sódio, o qual atua através de G-proteína(s), encontra-se comprometido. Estes experimentos indicam que o comprometimento da produção de EDRF/NO mediada por receptores após a lesão de reperfusão possa ser devido a uma disfunção de G-proteínas que liga os receptores da célula endotelial à via da síntese de EDRF/ NO;2) Quarenta e cinco minutos de parada cardioplégica de coraçōes de cães, pela solução St.Thomas não comprometem a produçāo de EDRF/NO em artérias epicárdicas coronárias. Estudos farmacológicosin vitro semelhantes, testando-se os efeitos da solução UW, suportaram o conceito de que ela não lesa o endotélio coronariano sendo segura para a preservação cardiaca durante transplantes cardiacos;3) Em segmentos de artérias coronárias, renais, femorais, e em segmentos de artéria pulmonar, a protamina induziu vasodilatação endotélio-dependente, mediada pela estimulação da liberação de EDRF/NO. Nas circulações coronariana e sistêmica, ao contrário do que se verificou nos experimentos envolvendo a circulação pulmonar, este efeito foi independente da presença de heparina; 4) Em $83 \%$ dos ensaios biológicos, o efluente da AMI esquerda induziu um relaxamento maior do anel coronariano bioensaiado do que o efluente da AMI direita, por liberação basal de EDRF/NO. Este inibe a adesividade e a agregação plaquetárias e a aterogêne, contribuindo para os resultados superiores obtidos quando se utiliza esta artéria para a revascularização do miocárdio. Quando expostos à hipóxia, as atividades vasodilatadoras da AMI e da veia safena foram maiores. Esta acentuação da vasodilataçāo causada pela hipóxia foi inibida pelo tratamento com a indometacina, e, ràpidamente, revertida, quando se restabeleceu a normóxia.

DESCRITORES: endotélio vascular, cirurgia cardiaca; óxido nítrico, fator relaxante endotelial.

\section{INTRODUÇÃO}

Apresentam-se neste trabalho, alguns aspectos relacionados ao paciente submetido a cirurgia cardíaca com circulação extracorpórea (CEC). Neste contexto serão apresentados estudos relativos a: a) disfunção endotelial aguda após isquemia global e reperfusão; b) possíveis efeitos sobre a função endotelial da hipotermia e do uso de duas soluções consagradas em cirurgia cardíaca (solução cardioplégica cristalóide tipo St.Thomas e solução da Universidade de Winscosin, preservativa de órgãos para transplantes); c) possíveis efeitos da protamina e do complexo protamina-heparina em artérias sistêmicas e nas circulações coronariana e pulmonar; e d) estudos da função endotelial, utilizando-se ensai-

Trabalho realizado na Mayo Clinic and Mayo Foundation. Section of Cardiovascular Surgery, Cardiac Surgical Research. Rochester, Minnesota, U.S.A. Apoio: CNPq - Conselho Nacional de Desenvolvimento Científico e Tecnológico do Brasil.

Apresentado ao $20^{\circ}$ Congresso Nacional de Cirurgia Cardiaca. Maceió - Al, 2 e 3 de Abril de 1993.

- Da Faculdade de Medicina de Riberāo Preto da Universidade de São Paulo.

Senior Fellow in Research. Mayo Clinic and Mayo Foundation.

* Da Mayo Clinic and Mayo Foundation. Section of Cardiovascular Surgery, Cardiac Surgical Research.

Endereço para separatas: Paulo Roberto B. Évora, Rua Rui Barbosa, 455, Apto. 140. 14015-120, Ribeirāo Preto, SP, Brasil. 
ÉVORA, P.R.B.; PEARSON, P.J.; SCHAFF, H.V. - Alguns aspectos da funçāo endotelial em cirurgia cardiaca. Rev. Bras. Cir. Cardiovasc., 8(3): 195-214, 1993.

os biológicos, de artérias mamárias internas e de veias safenas, que se constituem na grande maioría de condutos vasculares utilizados para revascularização do miocárdio.

\section{MATERIAL E MÉTODOS}

\section{Descrição da Metodologia}

Os estudos farmacológicos da função endotelial foram realizados in vitro utilizando-se o sistema de "organ chambers" e ensaio biológico.

As respostas endotélio-dependentes, de um modo geral, foram estudadas em segmentos vasculares, utilizando-se vários antagonistas os quais podem mimetizar a ativação dos passos específicos conhecidos da produção do fator relaxante endotelial ("Endothelium-derived relaxing factor" - EDRF). Para estímulos externos (receptor-dependentes) utilizaram-se: acetilcolina e o ADP e a protamina. $O$ íon fluoreto foi utilizado para estimular G-proteina, a fosfolipase $\mathrm{C}$ exógena foi utilizada para ativar a via fosfatidilinositol e o cálcio ionóforo A23187 para mimetizar a ação do inositol trifosfato $\left(\mathrm{IP}_{3}\right)$, e em última instância, medir a capacidade da célula endotelial produzir EDRF. Para o estudo da função da musculatura lisa vascular utilizaram-se o nitroprussiato de sódio (GMP cíclico) e o isoproterenol (AMP cíclico).

\section{Protocolo Para os Estudos da Função Endotelial} Após Isquemia Global e Reperfusão

Cães mestiços livres de verminose $(25-30 \mathrm{~kg})$ de ambos os sexos foram anestesiados com pentobarbital sódico $(30 / \mathrm{mg} / \mathrm{kg}$, bolo endovenoso; Ford Dodge Laboratories), intubados com uma sonda traqueal com balão e ventilados com $95 \%$ de oxigênio. Através de uma toracotomia direita instituiu-se circulação extracorpórea com 45 minutos de clampeamento aórtico (isquemia global) seguida de 60 minutos de reperfusão, após os quais os cães foram exsangüineados para o reservatório de cardiotomia. Após este período, excisou-se o coração, ainda com batimentos espontâneos, transferindo-o para uma solução fisiológica gelada e oxigenada com a seguinte composição milimolar: $\mathrm{NaCL}, 118.3 ; \mathrm{KCl}, 4.7 ; \mathrm{MgSO}_{4}$, 1.2; $\mathrm{KH}_{2} \mathrm{PO}_{4}, 1.22 ; \mathrm{CaCl}_{2}, 2.5 ; \mathrm{NaHCO}_{3}, 25.0 \mathrm{e}$ glicose, 11.1 (solução controle). Para o controle dos efeitos da circulação extracorpórea, realizaram-se experimentos semelhantes, com exceção do clampeamento aórtico e isquemia global. Em um outro grupo, utilizado para controle normal, os cães foram anestesiados, exsangüineados e os corações foram excisados e imersos em solução salina fisiológica oxigenada.

As artérias coronárias esquerdas circunflexa e descendente anterior dos corações reperfundidos e controles (normal e submetidos a circulação extracorpórea sem clampeamento aórtico) foram, cuidadosamente, dissecadas e colocadas em solução fisiológica. Tomou-se o cuidado de remover o tecido conjuntivo perivascular o máximo possível. Obtiveram-se, então, oito anéis vasculares $(4-5 \mathrm{~mm})$, removendo-se o endotélio de quatro deles, ficandose, assim, com um conjunto de quatro pares de anéis coronarianos com e sem endotélio. Realizouse a remoção do endotélio, por técnica padronizada, com auxílio de delicadas pinças microvasculares introduzidas na luz do anel coronariano e, esfregando-se em toalha de papel embebida em solução fisiológica.

Estudaram-se, em paralelo, anéis coronarianos (com e sem endotélio) de artérias reperfundidas, artérias expostas apenas à circulação extracorpórea sem clampeamento aórtico, e artérias controles. Adicionou-se indometacina $\left(10^{-5} \mathrm{M}\right)$ ao banhos das "organ chambers" 45 minutos antes dos experimentos, para prevenir a síntese de prostanóides. Se um conjunto de anéis coronarianos foi utilizado para testar mais de um agonista, observou-se um período de pelo menos trinta minutos entre os protocolos experimentais para cada preparação.

Utilizaram-se as seguintes drogas: cloridrato de acetilcolina, difosfato de adenosina (ADP), cálcio ionóforo A23187, ( \pm ) hidrocloreto de isoproterenol, indometacina, fosfolipase C (tipo II: de C. perfringens), prostaglandina $\mathrm{F}_{2 \mathrm{a}}$, fluoreto de sódio (Sigma Chemical Company, St. Louis, MO), e cloridrato de alumínio ( Aldrich Chemical Company, Milwaukee, Wi.). Todas as drogas foram preparadas diariamente com água destilada, exceto a indometacina, que foi dissolvida em $\mathrm{Na}_{2} \mathrm{CO}^{3}\left(10^{-5}\right)$, e o cálcio ionóforo, que foi dissolvido em dimetilsulfóxido (Sigma) e diluído em água destilada. As concentrações foram apresentadas concentração final molar (M) nas nas "organ chambers".

\section{Protocolo Para o Estudo dos Efeitos de Soluções Especiais Sobre a Função Endotelial}

Para estes estudos a preparação animal e os experimentos in vitro seguiram, de uma maneira geral, os mesmos principios descritos para os estudos da função endotelial após isquemia global e reperfusão.

Estudaram-se, em paralelo, segmentos de artérias coronárias (com e sem endotélio) de um mesmo animal em um conjunto de oito "organ- 
ÉVORA, P.R.B.; PEARSON, P.J.; SCHAFF, H.V. - Alguns aspectos da funçāo endotelial em cirurgia cardiaca. Rev. Bras. Cir. Cardiovasc., 8(3): 195-214, 1993.

chambers". Pares destes segmentos foram usados em um de cinco protocolos. Para o estudo do efeito de solução cardioplégica hipotérmica na artéria coronária, um par de anéis coronarianos foi exposto a solução cardioplégica (Plegisol, Abbott Laboratories, North Chicago, Illinois, $7^{\circ} \mathrm{C}$ ) por 45 minutos. Esta temperatura e o intervalo de tempo de exposição foram escolhidos para mimetizar condições clinicamente relevates. Para isolar-se só o efeito da solução cardioplégica, outro par de anéis coronarianos foi exposto a cardioplegia normotérmica pelos mesmos quarenta e cinco minutos $\left(37^{\circ} \mathrm{C}\right)$. Para controlar-se a influência da hipotermia, um par adicional de anéis foi exposto a hipothermia $\left(7^{\circ} \mathrm{C}\right)$ por 45 minutos. Para estudarem-se os efeitos da cardioplegia hipercalêmica, um quarto par de segmentos coronarianos foi exposto à solução cardioplégica normotérmica com concentração elevada de potássio ( $45 \mathrm{mEq} / \mathrm{L}$ ) por 45 minutos. Finalmente, um outro par de anéis foi, simplesmente, exposto a solução fisiológica controle, durante o mesmo tempo dos pares anteriores. Após os períodos de exposição acima descritos, as "organ chambers" foram lavadas com solução fisiológica contrôle, e os anéis coronarianos foram suspensos e submetidos ao processo de tensão-estiramento até $10 \mathrm{~g}$ antes da admnistração da drogas em presença de indometacina para bloqueio da via da ciclooxigenase.

Em um grupo adicional, animais foram anestesiados e ventilados com auxilio de respirador. Através de uma toracotomia lateral direita, as veias cavas foram enlaçadas e ocluídas. A aorta foi, então, pinçada, procedendo-se à infusão de cardioplegia cristalóide hipotérmica $\left(7^{\circ} \mathrm{C}\right)$ através de uma cânula na raíz aórtica a um fluxo tal que mantinha a pressão a/ortica proximal entre 90 e $120 \mathrm{mmHg}$. Após esta infusão, o coração foi excisado, mantido em solução salina fisiológica por 45 minutos, procedendo-se ao preparo das artérias coronári-as para o estudo em "organ chambers". Utilizaram-se as seguintes drogas: acetilcolina cloridrato, adenosina difosfato (ADP), indometacina, fluoreto de sódio, prostaglandina $F_{2 a}$, nitroprussiato de sódio e $( \pm)$ cloridrato de isoproterenol (todas da Sigma Chemical Company, St. Louis, Missouri). Preparou-se, diàriamente, uma solução cardioplégica comercial (Plegisol, Abbott Laboratories, North Chicago, Illinois), adicionando-se $10 \mathrm{ml}$ de bicarbonato de sódio $8,4 \%$ a $1000 \mathrm{ml}$ da solução cardioplégica, obtendose a seguinte composição final $(\mathrm{mEq} / \mathrm{l})$ : cálcio 2.4 , magnesium 3.2, potássio 16 , sódio 120 , e cloro 160 . Para o preparo da solução cardioplégica hipercalêmica, adicionou-se clorêto de potássio para uma concentração final de $45 \mathrm{mEq} / \mathrm{L}$. As soluções foram mantidas a $7^{\circ} \mathrm{C}$ até o momento de seu uso.

Utilizou-se idêntico protocolo, à exceção de in- fusão, para o estudo dos efeitos da solução UW sobre a função endotelial de artérias caninas epicárdicas.

\section{Protocolo Para o Estudo dos Efeito da Protamina e Complexo Protamina/Heparina Sobre a Função Endotelial Arterial}

Nestes estudos, realizados em "organ chambers", utilizaram-se anéis vasculares de artérias coronarianas caninas, anéis de ramos de terceira ordem da artéria pulmonar e, para o estudo da circulação sistêmica, escolheram-se as artérias renal e femoral. Utilizaram-se as seguintes drogas: cloridrato de acetilcolina, indometacina, prostaglandina $F_{2 a}$ (Sigma Chemical company, St. Louis, Missouri), L-arginina, D-arginina, e $\mathrm{N}^{\mathrm{G}}$-monomethylL-arginina (L-NMMA) (Calbiochem, San Diego, California), heparina sodica injetavel 2(bovina, $1000 \mathrm{U} / \mathrm{ml}$, Upjohn Company, Kalamazoo, Michigan), sulfato de protamina injetável $(10 \mathrm{mg} / \mathrm{ml})$, e sulfato de protamina em pó (100 U/mg, lot\#05925, ElkinsSinn Inc, Cherry Hill, New Jersey). Adicionou-se o sulfato de protamina nas "organs chambers" em um modo cumulativo de 11 doses de tal forma que a variação estudada foi de 40 a $400 \mu \mathrm{g} / \mathrm{ml}$.

\section{Ensaio Biológico de Artérias Mamárias Esquerda e Direita e de Veias Safenas}

Realizaram-se ensaios biológicos comparativos de segmentos de artérias mamárias caninas direita e esquerda (aproximadamente $5 \mathrm{~cm}$ ). Realizaramse, também, comparações entre artéria mamária e via safena caninas. A atividade biológica do EDRF foi bioensaiada, utilizando-se um anel de artéria coronária circunflexa com seu endotélio mecanicamente removido. As artérias mamárias internas foram perfundidas com um fluxo constante de $5 \mathrm{ml} / \mathrm{min}$ com solução salina fisiológica a $37^{\circ} \mathrm{C}$. As atividades tensionais desenvolvidas pelo anel de ensaio biológico foram registradas para a quantificação dos efeitos produzidos pela liberação de fatores vasoativos do endotélio dos segmentos de artérias mamárias internas perfundidas a um fluxo constante. $O$ anéis coronarianos sem endotélio ("bioassay rings") foram, inicialmente, superfundidos por cerca de 60 minutos, durante os quais obtiveram-se seus pontos ótimos de tensão-estiramento $(10 \mathrm{~g})$. Após este período, aguardados 30 minutos, contraíramse os "bioassay rings" pela superfusão de prostaglandina $F_{2 \alpha}$. A ausência de endotélio nestes anéis foram confirmadas pela injeção de acetilcolina na linha direta do sistema de superfusão. Após todos estes cuidados técnicos, os "bioassay rings" foram testados pelos efeitos obtidos pela superfusão através dos segmentos das artérias mamárias 
ÉVORA, P.R.B.; PEARSON, P.J.; SCHAFF, H.V. - Alguns aspectos da função endotelial em cirurgia cardiaca. Rev. Bras. Cir. Cardiovasc., 8(3): 195-214, 1993.

(superfusão endotelial). Em alguns experimentos removeram-se o endotélio de ambas artérias mamárias utilizando-se um pequeno probe de aço inoxidável. Sempre que se utilizou este expediente, testou-se a ausência de endotélio pela injeção de acetilcolina (10-7 M). Após os estudos os segmentos de artérias mamárias e veias safenas foram preservados em formalina, abertos longitudinalmente, fixados em cartões e fotografados. As superfícies destes vasos foram, então, medidas com auxílio de planimetria assistida por computador.

Utilizaram-se as seguintes drogas: cloridrato de acetilcolina, indometacina, prostaglandina $F_{2 \alpha}$ (Sigma Chemical Company, St. Louis, Missouri); NG-nitro$\mathrm{L}$-arginina e $\mathrm{N}$-monometil-L-arginina (Calbiochem, San Diego, California). Considerou-se, para este estudo comparativo, apenas a liberação basal do EDRF/NO e o seu bloqueio por inibidores da NOsintetase, além do efeito da remoção do endotélio dos segmentos de artérias mamárias. Neste estudos comparativos testou-se, também, o efeito da hipóxia.

Os procedimentos para experimentação animal foram revisados e aprovados pelo Intitutional Animal Care and Use Committee da Mayo Foundation.

\section{Análise dos Dados}

Os resultados serão apresentados como médias \pm êrro-padrão. Em todos os experimentos, $n$ significa o número de animais dos quais os anéis vasculares foram obtidos. Em anéis contraídos com prostaglandin $\mathrm{F}_{2 \alpha}$, as respostas foram expressas como percentagem das alterações a partir da contração máxima estável. Estes valores foram utilizados para a construção de curvas dose-resposta. Para a análise estatística foram utilizados a análise de variança (ANOVA) e o teste $T$ de Student para observações pareadas e não pareadas. Os valores foram considerados significantes quando o valor de $P$ foi menor do que 0.05 .

\section{RESULTADOS}

\section{Função Endotelial Após Isquemia Globale Reperfusão}

A acetilcolina $(\mathrm{ACH})(10-9$ a $10-4 \mathrm{M})$ e o difosfato de adenosina (ADP) (10-9 a 10-4 M) causaram relaxamento endotélio-dependente em artérias coronárias contrôles e reperfundidas. Entretanto, o relaxamento em artérias reperfundidas, mostrou-se comprometido com desvio para a direita da curva doseresposta (Gráfico 1).

O fluoreto de sódio (NaF) (0.5 a $11.5 \mathrm{nM})$ in-
GRÁFICO 1

RELAXAMENTOS RECEPOR-DEPENDENTES

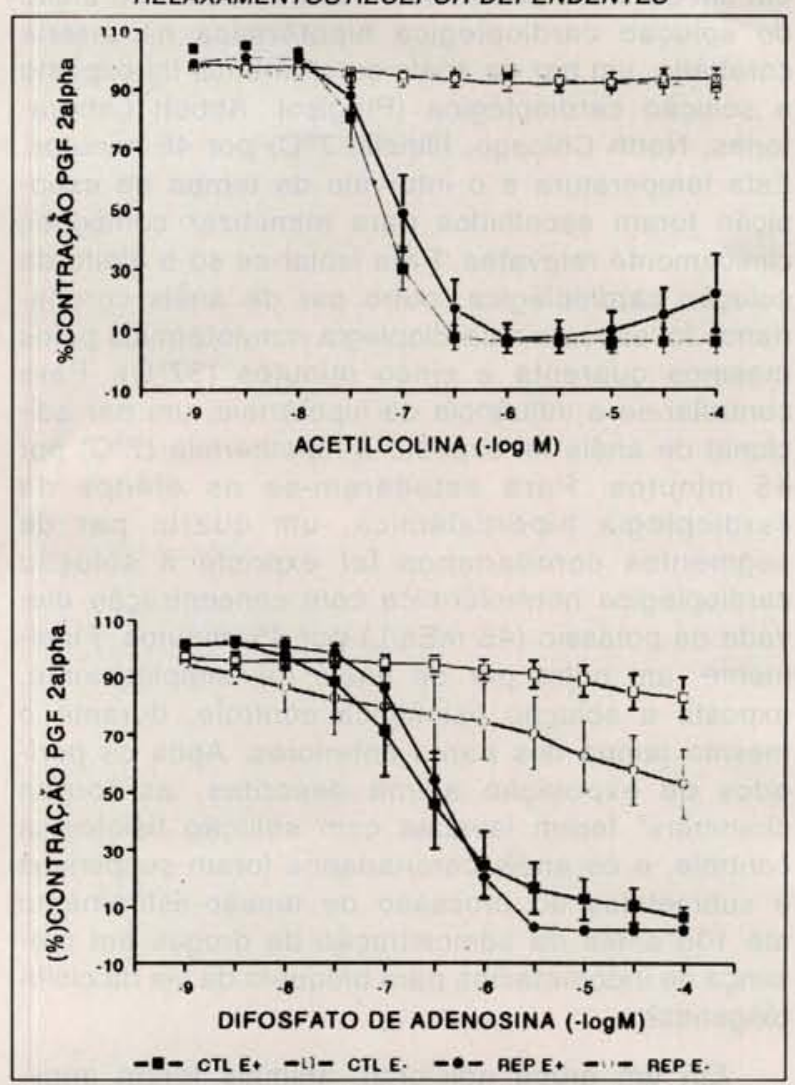

Curvas dose-respostas à acetilcolina ( $\mathrm{ACH}$ ) (superior) e disfosfato de adenosina ( $A D P$ ) (inferior) em segmentos arteriais controles e reperfundidos com e sem endotélio $(\mathrm{N}=8)$. Os anéis foram primeiro contraídos com prostaglandina $F_{2 \alpha}$ edepois expostos a concentrações crescentes de AC e ADP. Apresentam-se os resultados sob a forma de média \pm erropadrão.

duziu relaxamento concentração-dependente em artérias coronárias caninas contraídas com prostaglandina $F_{2 \alpha}$ (Gráfico 2). Entretanto, a exposição ao $\mathrm{NaF}$ aumentou a tensão em artérias coronárias sem endotélio. Cloreto de alumínio $(10 \mu \mathrm{M}$, adicionado ao banho das "organ chambers" 5 minutos antes da adição do $\mathrm{NaF}^{\prime \prime}$ ) não alterou significantemente o relaxamento ao $\mathrm{NaF}$ ( $n=4$, dado não apresentado). Em artérias coronarianas de corações expostos a circulação extracorpórea sem clampeamento aórtico ou isquemia miocárdica global, o NaF induziu relaxamentos em anéis com endotélio e nenhuma alteração na tensão de anéis sem endotélio. Esta resposta foi comparável em artérias contrôles não manipuladas (Gráfico 2). Em contraste, segmentos de artérias coronarianas de corações expostos a isquemia global e reperfusão durante o clampeamento aórtico, o relaxamento endotélio-dependente causado pelo NaF em artérias com endotélio foi, significantemente, menor do que o relaxamento apresentado por artérias de corações contrôles e corações expostos a circulação extracorpórea sem 
ÉVORA, P.R.B.; PEARSON, P.J.; SCHAFF, H.V. - Alguns aspectos da função endotelial em cirurgia cardiaca. Rev. Bras. Cir. Cardiovasc., 8(3): 195-214, 1993.

GRÁFICO 2

TRANSDUÇĀO: G-PROTEINAS

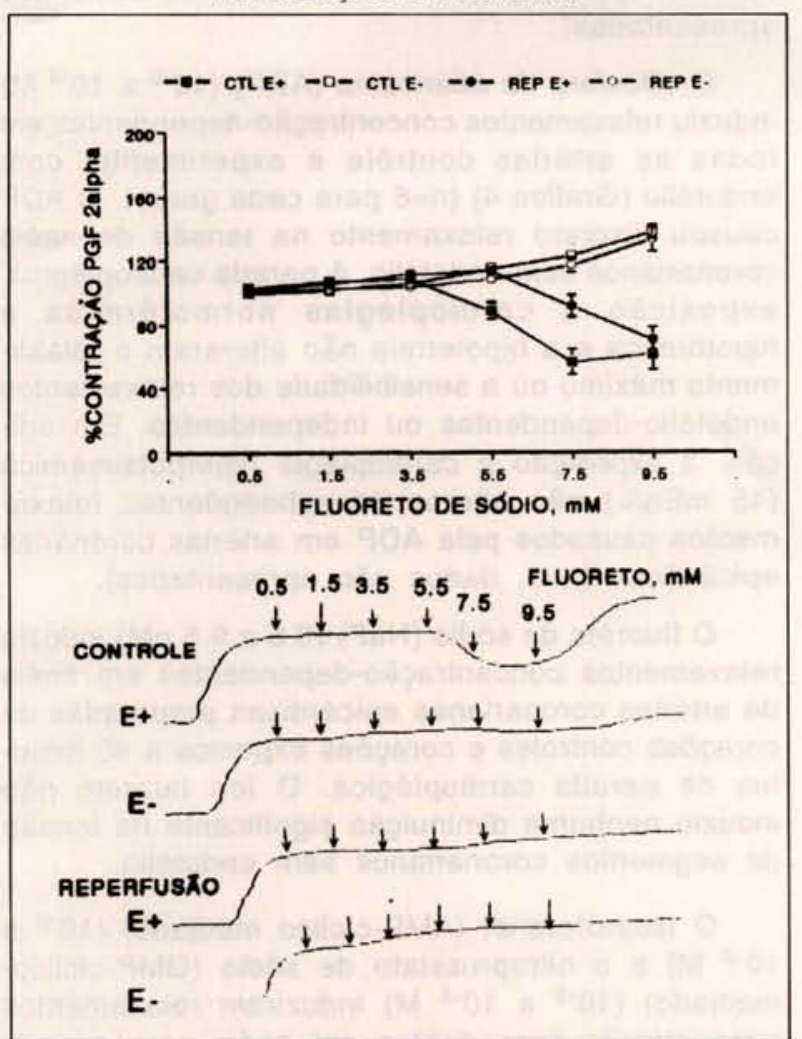

Curvas dose-respostas ao fluoreto de sódio (NaF) ( $\mathrm{N}=12$, superior) em segmentos arteriais coronarianos controles (circulação extracorpórea sem clampeamento aórtico) e reperfundidos (isquemia global induzida pelo clapeamento aórtico), com e sem endotélio. Os anéis vasculares foram primeiro contraídos com prostaglandina $F_{2 \alpha}$ e então expostos a concentrações crescentes de NaF. Apresentam-se os resultados sob a forma de média \pm erro-padrão. Traçados originais de tensões isométricas de relaxamentos endotélio-dependentes produzidos pelo floureto de sódio (NaF) em segmentos arteriais coronarianos controle (traçado superior) e reperfundidos (traçado inferior). Os segmentos arteriais foram primeiro contraidos com prostaglandina F2 $\alpha$ e então expostos a concentraçōes crescentes de NaF (inferior).

clampeamento aórtico (Gráfico 2). Não houve nenhuma diferença significante, na resposta ao $\mathrm{NaF}$, entre artérias contrôles e reperfundidas sem endotélio.

O cálcio ionóforo A23187 (10-9 a $\left.10^{-6} \mathrm{M}\right)$ e a fosfolipase $C(0.01$ a $0.7 \mathrm{U} / \mathrm{ml})$ induziram relaxamentos concentrações-dependentes em artérias controles e reperfundidas com endotélio (Gráfico 3 ). Estes dois agonistas não causaram nenhuma alteração na tensão em coronárias sem endotélio. Não houve nenhuma diferença nas respostas entre segmentos vasculares controles e reperfundidos.

$\mathrm{O}$ isoproterenol (AMP-cíclico mediado) $\left(10^{-9}\right.$ a $10^{-4} \mathrm{M}$ ) e o nitroprussiato de sódio (GMP-cíclico mediado) $\left(10^{-9}\right.$ a $\left.10^{-4} \mathrm{M}\right)$ induziu relaxamentos concentração-dependentes comparáveis em artéri- as controles e reperfundidas com e sem endotélio. Não houve nenhuma diferença significante, em relaxamentos produzidos, dentro de cada grupo (com e sem endotélio) ou entre cada grupo (controle e reperfundido) (resultados não mostrados sob a forma de figuras). A prostaglandina $F_{2 \alpha}$ (receptor-dependente) $\left(10^{-8} \mathrm{M}\right)$ induziu contrações comparáveis em anéis coronarianos com e sem endotélio (5.52 \pm 0.57 e $4.82 \pm 0.35$ gramas, respectivamente, $\mathrm{n}=6$ ) e em artérias reperfundidas com e sem endotélio $(6.19 \pm 0.91$ e $5.40 \pm 1,12$ gramas, respectivamente, $n=7$ ). Não houve nenhuma diferença significante, nas contrações induzidas pela prostaglandina $F_{2 \alpha}$, dentro de cada grupo (com e sem endotélio) ou entre os grupos controles e reperfundidos. O mesmo ocorreu com as contrações induzidas pela endotelina-1 (receptor-dependente) e pelo clorêto de potássio (voltagem-dependente) (resultados não mostrados sob a forma de figuras).

GRÁFICO 3

\section{RELAXAMENTOSRECEPOR-DEPENDENTES}
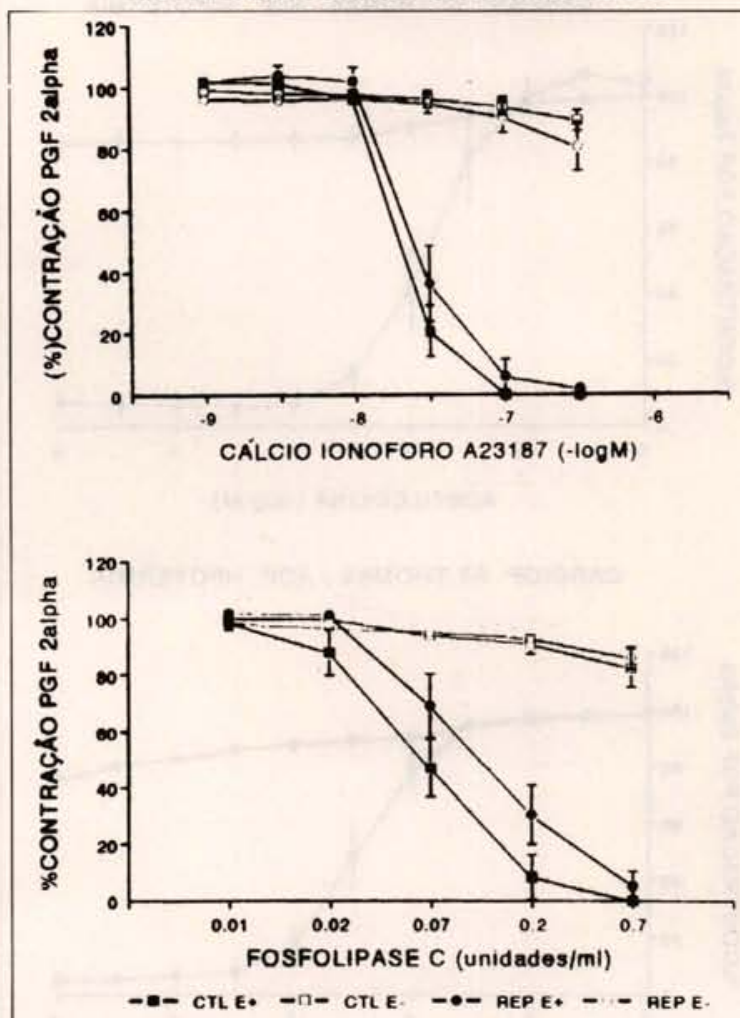

Curvas dose-respostas ao cálcio ionóforo $\mathrm{A} 23187(\mathrm{~N}=6$, superior) e à fosfolipase $\mathrm{C}$ (tipo II de espécies vibrio) $(\mathrm{N}=6$, inferior) em segmentos arteriais coronarianos controles (circulação extracorpórea sem clampeamento aórtico) e reperfundidos (isquemia global induzida pelo clampeamento aórtico), com e sem endotélio. Os anéis vasculares foram primeiro contraidos com prostaglandina $\mathrm{F}_{2 \alpha}$ e então expostos a concentraçōes crescentes das drogas. Apresentam-se os resultados sob forma de média \pm erro-padrão. 
ÉVORA, P.R.B.; PEARSON, P.J.; SCHAFF, H.V. - Alguns aspectos da funçāo endotelial em cirurgia cardiaca. Rev. Bras. Cir. Cardiovasc., 8(3): 195-214, 1993.

Função Endotelial, Soluções e Hipotermia.

\section{Solução cardioplégica cristalóide (St.Thomas)}

A acetilcolina $(\mathrm{ACH})\left(10^{-9}\right.$ a $\left.10^{-4} \mathrm{M}\right)$ induziu relaxamentos concentração-dependentes em todos os segmentos de artérias coronarianas com endotélio ( $n=6$ para cada grupo). $A$ ACH não produziu nenhuma alteração significante nas tensões de anéis coronarianos sem endotélio (Gráfico 4). Parada cardioplégica, exposição a cardioplegia hipotérmica ou a cardioplegia normotérmica não alterou o relaxamento máximo ou a sensibilidade do relaxamento induzido pela acetilcolina em segmentos coronarianos com endotélio. Em adição, a exposição a solução cardioplégica com alta concentração de potássio ( $45 \mathrm{mEq} / \mathrm{L})$ não alterou subsequentes relaxa-

GRÁFICO 4

RELAXAMENTOS RECEPOR-DEPENDENTES

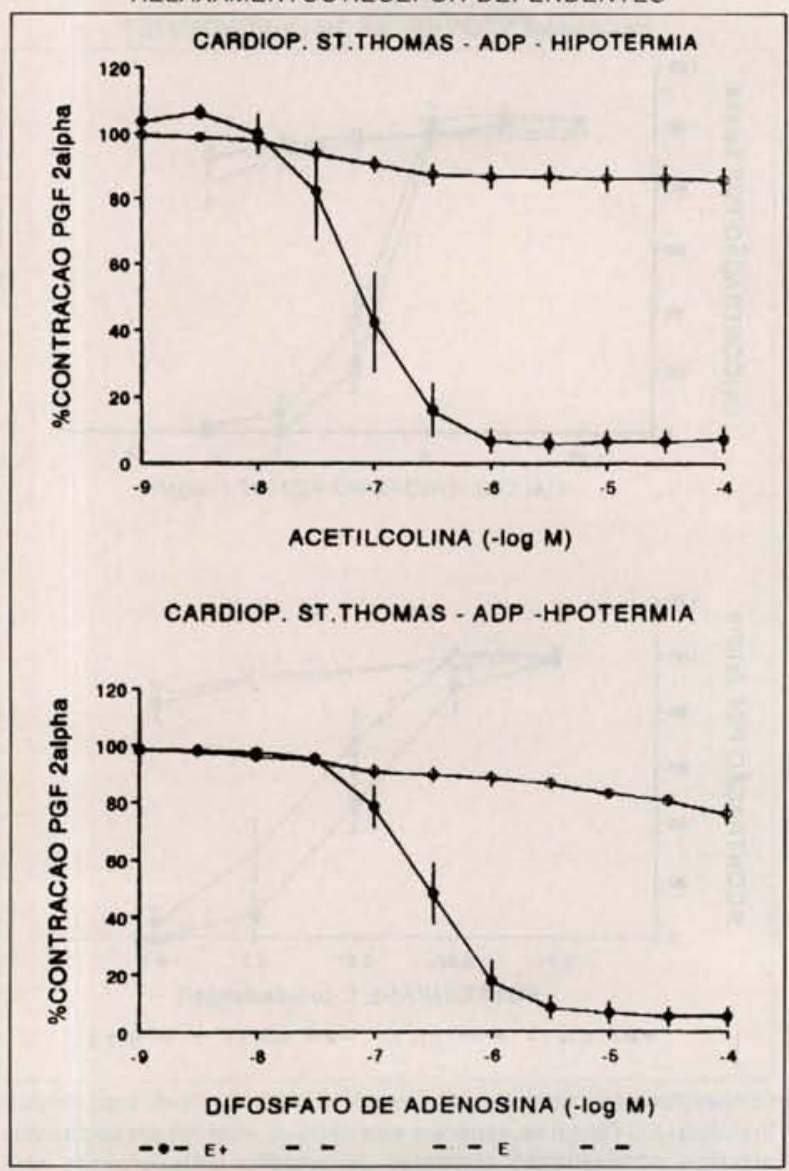

Curvas dose-respostas normais à acetilcolina $(\mathrm{ACH})(\mathrm{N}=6$, superior) e ao difosfato de adenosina ( $A D P)$ ( $N=6$, inferior) em segmentos arteriais coronarianos come sem endotélio expostos à solução cardioplégica (ST. Thomas) a $7^{\circ} \mathrm{C}$ durante 45 minutos. Apresentam-se os resultados sob a forma de média \pm erro-padrāo. mentos endotélio-dependentes a acetilcolina em artérias epicárdicas coronarianas $(n=4$, dado não apresentados).

O difosfato de adenosina (ADP) $\left(10^{-9}\right.$ a $\left.10^{-4} \mathrm{M}\right)$ induziu relaxamentos concentração-dependentes em todas as artérias contrôle e experimental com endotélio (Gráfico 4) ( $n=6$ para cada grupo). O ADP causou discreto relaxamento na tensão de anéis coronarianos sem endotélio. A parada cardioplégica, exposicão a cardioplegias normotérmica e hipotérmica e a hipotermia não alteraram o relaxamento máximo ou a sensibilidade dos relaxamentos endotélio-dependentes ou independentes. Em adição, a exposição a cardioplegia hiperpotassêmica (45 mEq/L) não alterou os subseqüentes relaxamentos causados pela ADP em artérias coronárias epicárdicas ( $n=3$, dados não apresentados).

O fluorêto de sódio (NaF) (0.5 a $9.5 \mathrm{nM}$ ) induziu relaxamentos concentração-dependentes em anéis de artérias coronarianas epicárdicas preparadas de corações controles e corações expostos a 45 minutos de parada cardioplégica. $O$ íon fluoreto não induziu nenhuma diminuição significante na tensão de segmentos coronarianos sem endotélio.

$\mathrm{O}$ isoproterenol (AMP-cíclico mediado) $\left(10^{-9}\right.$ a $10^{-4} \mathrm{M}$ ) e o nitroprussiato de sódio (GMP-cíclicomediado) $\left(10^{-9}\right.$ a $\left.10^{-4} \mathrm{M}\right)$ induziram relaxamentos concentração-dependentes em anéis coronarianos com e sem endotélio ( $n=6$ para cada grupo). A cardioplegia, cardioplegia hipotérmica e a hipotermia não alteraram a reatividade da musculatura lisa vascular ao isoproterenol (Gráfico 5 ).

O ion potássio (voltagem-dependente) (5 a 50 $\mathrm{mM}$ ) induziu comparáveis contrações concentraçãodependentes em anéis coronarianos com e sem endotélio nos grupos controle e experimental $(n=6$ para cada grupo). A cardioplegia hipotérmica, a hipotermia e a cardioplegia normotérmica não causaram nenhuma alteração significante na resposta máxima ou sensibilidade aos íons potássio. A prostaglandina $F_{2 \alpha}$ (receptor-dependente) $\left(10^{-9}\right.$ a $\left.10^{-5} \mathrm{M}\right)$ também induziu contrações concentração-dependentes comparáveis em artérias coronarianas epeicárdicas com e sem endotélio ( $n=6$ para cada grupo). A cardioplegia hipotérmica, a hipotermia e a cardioplegia normotérmica não causaram qualquer alteração significante na resposta máxima a prostaglandina $\mathrm{F}^{2 \alpha}$ ou alteração da reatividade vascular a este composto).

\section{Solução da Universidade de Winscosin (solução UW)}

A acetilcolina $(\mathrm{ACH})\left(10^{-9}\right.$ a $\left.10^{-4} \mathrm{M}\right)$ e o difosfato de adenosiana (ADP) $\left(10^{-9}\right.$ a $\left.10^{-4} \mathrm{M}\right)$ induziram relaxamentos concentração-dependentes em seg- 
GRÁFICO 5

RELAXAMENTOSENDOTELIO-INDEPENDENTES

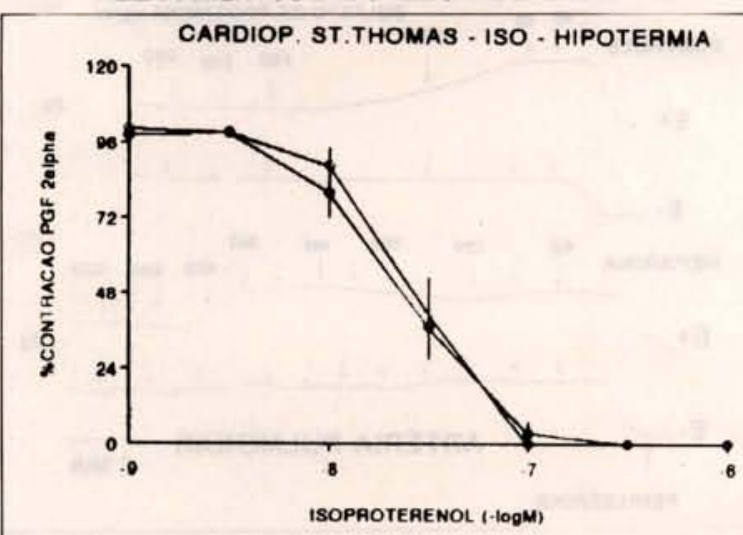

CARDIOP. ST.THOMAS - NPS - NORMOTERMIA

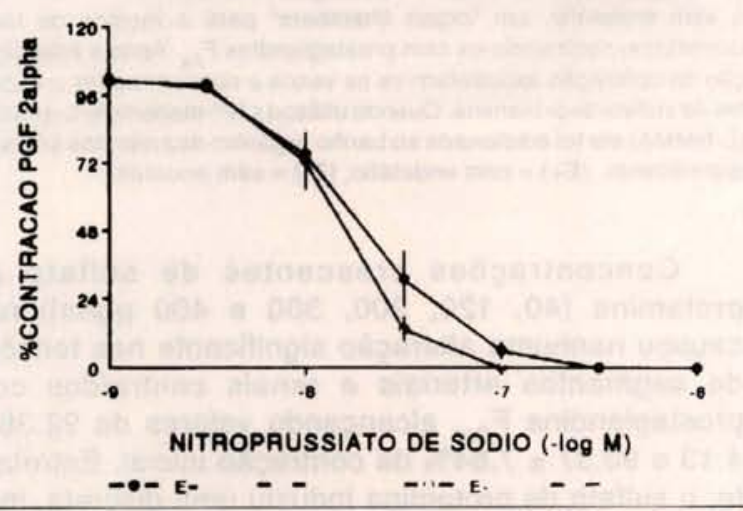

Curvas dose-respostas normais ao isoproterenol (ISO) ( $\mathrm{N}=6$, superior) e ao nitroprussiato de sódio (NPS) ( $\mathrm{N}=6$, inferior) em segmentos arteriais coronaianos come sem endotélio expostos à soluçăo cardioplégica (ST. Thomas), respectivamente a $7^{\circ} \mathrm{C}$ e $37^{\circ} \mathrm{C}$, durante 45 minutos. Apresentam-se os resultados sob a forma de média \pm erro-padrão.

mentos arteriais coronarianos, contrôles e experimentais, com endotélio ( $n=6$ para cada grupo). Não produziram nenhuma alteração significante na tensão de anéis coronarianos sem endotélio. Exposição a solução UW hipotérmica, hipotermia ou solução UW normotérmica não conprometeu o relaxamento máximo ou a sensibilidade dos relaxamentos produzidos pela $\mathrm{ACH}$ e pelo $\mathrm{ADP}$ em segmentos arteriais com endotélio (Gráfico 6).

$\mathrm{O}$ isoproterenol (AMP-cíclico mediado) $\left(10^{-9}\right.$ a $10^{-4} \mathrm{M}$ ) e o nitroprussiato de sódio (GMP-cíclico mediado) $\left(10^{-9}\right.$ a $\left.10^{-4} \mathrm{M}\right)$ induziram relaxamentos concentração-dependentes em segmentos coronarianos, controles e experimentais, sem endotélio $(n=6$ para cada grupo). A solução UW, hipotermia e solução UW normotérmica não alteraram o relaxamento máximo ou a sensibilidade da musculatura lisa vascular ao isoproterenol (Gráfico 7).

O cácio ionóforo (A23187) $\left(10^{-9}\right.$ a $10^{-6} \mathrm{M}$ induziu relaxamentos concentração-dependentes em todas a artérias controle e experimental com
GRÁFICO 6

RELAXAMENTOS RECEPOR-DEPENDENTES

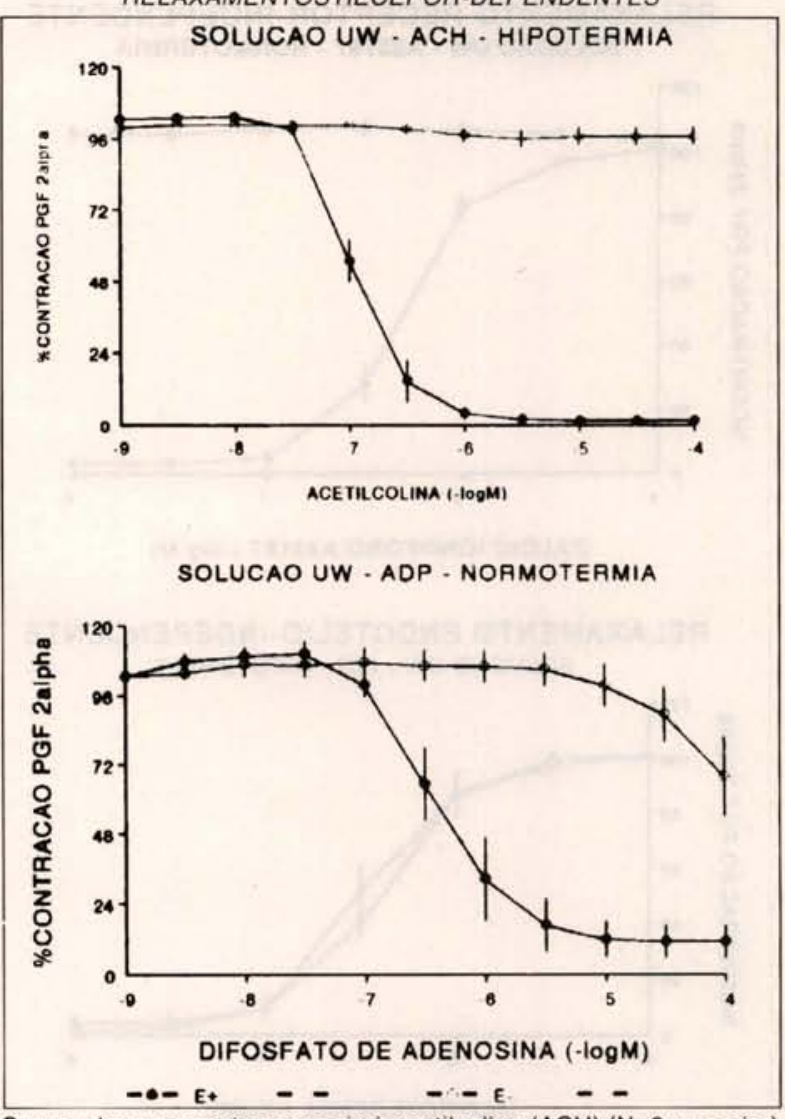

Curvas dose-respostas normais à acetilcolina $(\mathrm{ACH})(\mathrm{N}=6$, superior) e ao difostato de adenosina ( $A D P)(N=6$, inferior) em segmentos arteriais coronarianos com e sem endotélio expostos à soluçăo da Universidade de Winsconsin (Solução UW), respectivamente a $7^{\circ} \mathrm{C}$ e $37^{\circ} \mathrm{C}$, durante 45 minutos. Apresentam-se os resultados sob a forma de média \pm erro-padrão.

endotélio ( $n=6$ para cada grupo). O relaxamento em artérias sem endotélio foi desprezível (Gráfico 7).

O íon potássio (voltagem-dependente) ( 5 a 50 $\mathrm{mM})$ e a prostaglandina $\mathrm{F}_{2 \mathrm{a}}$ (receptor-dependente) $\left(10^{-9}\right.$ a $\left.10^{-5} \mathrm{M}\right)$ induziram contração-dependente de anéis coronarianos, contrôles e experimentais, com e sem endotélio ( $n=6$ para cada grupo). Solução UW hipotérmica, hipotermia e solução UW normotérmica não causaram nenhuma alteração significante na resposta máxima ou sensibilidade ao íon potássio (dados não mostrados sob a forma de figuras).

Função Endotelial Arterial, Protamina e Protaminal Heparina.

\section{Circulações coronariana e sistêmica}

Como representantes da circulação sistêmica escolheram-se as artérias caninas renal e femoral. 
GRÁFICO 7

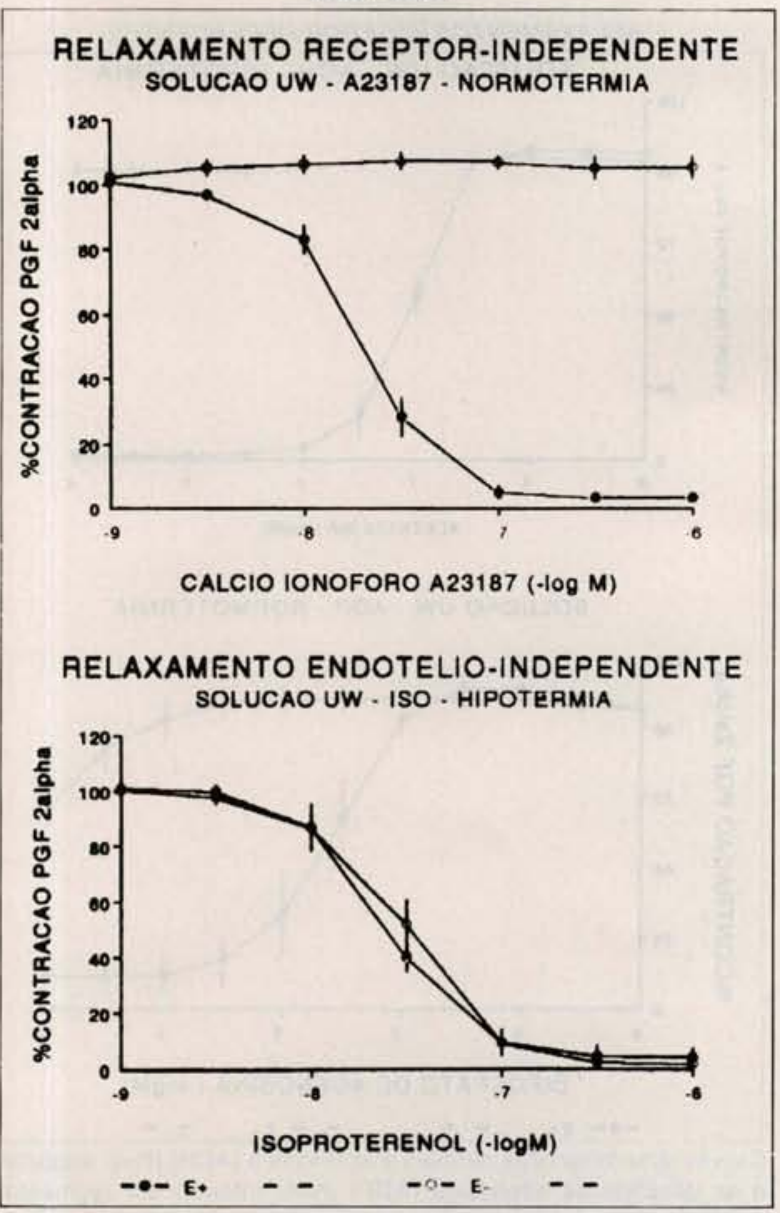

Curvas dose-respostas normais ao cálcio ionóforo (A23187) $(\mathrm{N}=6$, superior) e ao isoproterenol (ISO) ( $\mathrm{N}=6$, inferior) em segmentos arteriais coronarianos expostos com e sem endotélio à solução da Universidade de Winsconsin (Solução UW), respectivamente a $37^{\circ} \mathrm{C}$ e $7^{\circ} \mathrm{C}$, durante 45 minutos. Apresentam-se os resultados sob a forma de média \pm erro-padrăo.

Nas artérias renais, contraídas com prostaglandina $\mathrm{F}_{2 \alpha}$, a adição progressiva de sulfato protamina (concentrações finais nas "organ chambers" de 40, 120, 200,300 e $400 \mu \mathrm{g} / \mathrm{ml}$ ) produziu relaxamento sustentado em segmentos com endotélio (para protamina $400 \mu \mathrm{g} / \mathrm{ml}, \mathrm{p}<00.5$ ) (Gráfico 8). Entretanto, este mesmo procedimento não causou nenhuma alteração significante em segmentos de artérias renais sem endotélio. A adição de doses crescentes de sulfato de protamina (40 a $400 \mu \mathrm{g} / \mathrm{ml})$, nos banhos das "organ chambers" produziu progressivo relaxamento concentração-dependente em segmentos de vasos caninos renais, femorais e coronarianos com endotélio alcançando valores de $15.85 \pm 9.11,5.90$ \pm 10.01 e $5.91 \pm 11.04 \%$ da contração inicial produzida pela prostaglandina $\mathrm{F}_{2 \alpha}$. (respectivamente (média \pm êrro padrão, $\mathrm{p}<0.05$, comparada com 0 padrão das curvas concentração-resposta para segmentos arteriais sem endotélio).

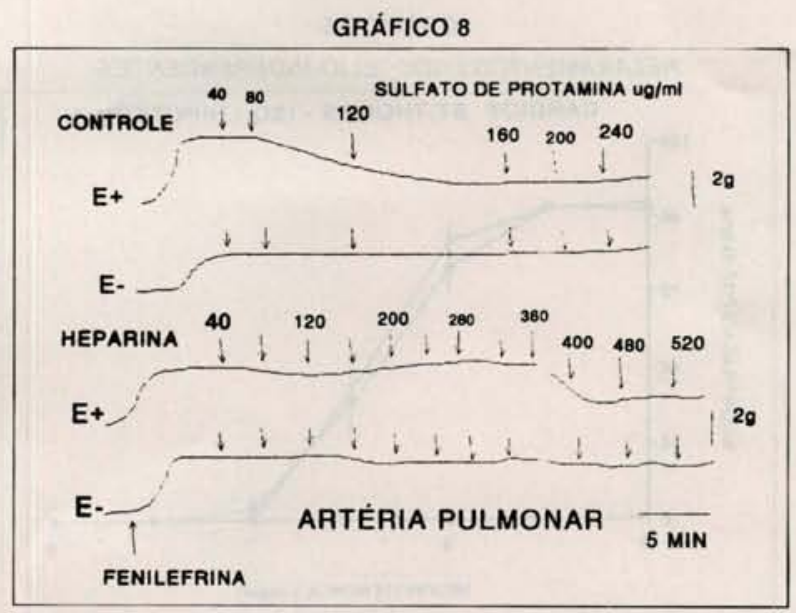

Efeito da protamina na tensão isométrica de artérias renais caninas (traçado original). Supenderam-se segmentos de artérias renais, com e sem endotélio, em "organ chambers" para a medida de força isométrica, contraindo-os com prostaglandina $\mathrm{F}_{2 \mathrm{a}}$. Após a estabilizaçāo da contração expuseram-se os vasos a concentraçōes crescentes de sulfato de protamina. Quando utilizou a $N^{G}$-monometil-L-arginina (L-NMMA) ela foi adicionada ao banho orgânico dez minutos antes do experimento. $(E+)=$ com endotélio; $(E-)=$ sem endotélio.

Concentrações crescentes de sulfato de protamina $(40,120,200,300$ e $400 \mu \mathrm{g} / \mathrm{ml})$ não causou nenhuma alteração significante nas tensões de segmentos arteriais e renais contraídos com prostaglandina $F_{2 \alpha}$, alcançando valores de $92.38 \pm$ 4.13 e $90.37 \pm 7.64 \%$ da contração inicial. Entretanto, o sulfato de protamina induziu uma discreta, mas significante, diminuinuição na tensão de artérias coronarianas sem endotélio alcançando $67.85 \pm$ $14.02 \%$ da contração inicial causada pela prostaglandina $\mathrm{F}^{2 \alpha}(\mathrm{p}<0.05)$.

$A$ adição de $\mathrm{N}$-monometil-L-arginina (L-NMMA) $\left(10^{-5} \mathrm{M}\right)$, o inibidor competitivo da produção de óxido nítrico a partir da L-arginina, dez minutos antes da contração com a prostaglandina $F_{2 \alpha}$, não induziu nenhuma alteração consistente na tensão arterial de segmentos com ou sem endotélio. Entretanto, o pré-tratamento dos anéis vasculares com o L-NMMA bloqueou, completamente, o relaxamento endotéliodependente, causado pela protamina, em segmentos de artérias renais (Gráfico 8) femorais e coronarianas. $\mathrm{O}$ efeito inibitório do L-NMMA pode ser revertido pela adição de $\mathrm{L}$-arginina $\left(10^{-4} \mathrm{M}\right)$ mas não pela $D$-arginina.

A heparina $(8 \mathrm{U} / \mathrm{ml}$ como concentração final no banho orgânico) não causou nenhuma alteraçào significante na tensão de segmentos arteriais contraídos com e sem endotélio. Entretanto, concentrações crescentes de heparina (até $60 \mathrm{U} / \mathrm{ml}$ ), causou uma diminuição significante na tensão de anéis contraídos de artérias femorais com e sem endotélio $(p<0,05)$. Relaxamentos comparáveis concentraçãodependentes foi encontrado em segmentos de ar- 
ÉVORA, P.R.B.; PEARSON, P.J.; SCHAFF, H.V. - Alguns aspectos da função endotelial em cirurgia cardiaca. Rev. Bras. Cir. Cardiovasc., 8(3): 195-214, 1993.

téria femoral com e sem endotélio a uma concentração de heparina de $60 \mathrm{U} / \mathrm{ml}$ alcançando valores de $38.7 \pm 8.6$ e $33.9 \pm 4.9 \%$ da contração inicial produzida pela prostaglandina $\mathrm{F}_{2 \alpha}$ (média \pm erro padrão, $n=6)$.

Nas "organ-chambers" contendo heparina (8 U/ $\mathrm{ml}$ ), a adição de sulfato de protamina (40 a $400 \mu \mathrm{g} /$ $\mathrm{ml}$ ) tornou turvo o líquido do banho, inicialmente claro, pela provável formação do complexo protamina-heparina. Entretanto, mesmo na presença de heparina, a adição de protamina causou relaxamento concentração-dependente em segmentos de artéria femoral com endotélio sem nenhuma alteração nos segmentos sem endotélio. Esta resposta foi comparável ao efeito da protamina em anéis de artéria femoral na ausência de heparina.

A L-arginina $\left(10^{-9}\right.$ a $\left.10^{-4} \mathrm{M}\right)$ não causou nenhuma alteração significante em segmentos de artéria femoral com e sem endotélio (alteração máxima = $109.7 \pm 6.9$ e $93.4 \pm 2.1 \%$, respectivamente, da contração inicial induzida pela prostaglandin $F_{2 \alpha}$ ) (média \pm êrro-padrão, $n=6$ ). Não se observou nenhum efeito endotélio-dependente mesmo com a Larginina mantida em contato com o tecido por um tempo superior a 40 minutos.

A D-arginina $\left(10^{-9}\right.$ a $\left.10^{-4} \mathrm{M}\right)$ induziu uma pequena diminuição na tensão de segmentos arteriais femorais com endotélio (alteração máxima de 113.5 $\pm 4.6 \%$ da contração inicial causada pela prostaglandina $F_{2 \alpha}$ ) e um discreto relaxamento nos segmentos sem endotélio (resposta máxima de 98.6 $\pm 3.7 \%$ da contração inicial) (média \pm erro padrão, $\mathrm{n}=6)$.

\section{Circulação pulmonar}

Em segmentos de artérias pulmonares com endotélio os quais foram contraídos com fenilefrina $\left(10^{-8} \mathrm{M}\right)$, a adição de sulfato de protamina induziu vasodilatação a qual foi, quase completamente neutralizada pelos efeitos vasoconstritores da fenilefrina na musculatura lisa vascular (anéis arteriais sem endotélio) (Gráfico 9 ). O sulfato de protamina (40 a $400 \mu \mathrm{g} / \mathrm{ml}$ ) produziu relaxamento concentração-dependente em segmentos de artéria pulmonar canina com endotélio $(74.00 \pm 7.00 \%$ da concentração inicial induzida pela fenilefrina, média \pm êrro padrão), o qual foi, significantemente maior do que o efeito causado em anéis arteriais sem endotélio $(p<0.05, n=7)$. O sulfato de protamina causou um modesto mas significante relaxamento em segmetos sem endotélio $(30.00 \pm 6.00 \%$ da contração inicial induzida pela fenilefrina, $\mathrm{p}<0.05)$.

O pré-tratamento dos segmentos arteriais com $\mathrm{N}^{\mathrm{G}}$-monometil-L-arginina (L-NMMA, $10^{-5} \mathrm{M}$ ), o
GRÁFICO 9

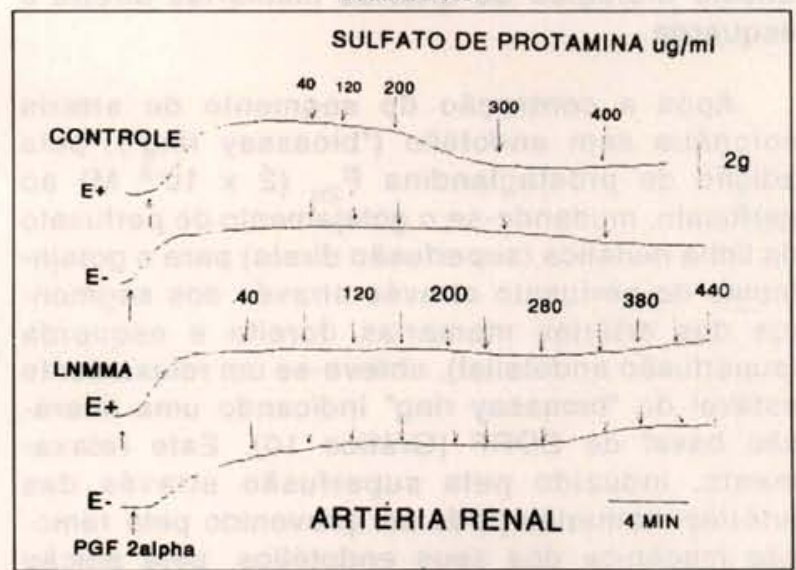

Traçado da tensāo isométrica do efeito do sulfato de protamina em artérias pulmonares caninas (traçado original). Suspenderam-se, em "organ chambers", segmentos de terceira ordem da artéria pulmonar, com e sem endotélio, para medida da força isométrica. Utilizou-se a fenilefrina $\left(10^{-6} \mathrm{M}\right)$ para as contraçōes dos anéis arteriais os quais foram expostos, após estabilização, a concentraçōes crescentes de sulfato de protamina. Em segmentos de artéria pulmonar com endotélio, a protamina induziu relaxamento concentração-dependente, o qual reverteu por completo a contração causada pela fenilefrina na musculatura lisa vascular (traçado superior). A heparina $(80 \mathrm{U} / \mathrm{ml})$ inibiu o relaxamento endotélio-dependente causado pela protamona ( 40 a 400 ug/ml), concentraçăo final no banho orgânico) (traçado inferior). Entretanto, com a adição de doses crescentes de protamina, foi possível reverter o efeito inibitório de heparina (traçado inferior) $(E+)=c o m$ endotélio; $(E-)$ = sem endotélio.

inibidor competitivo da síntese do óxido nítrico a partir da L-arginina, não alterou a tensão dos segmentos arteriais, mas o L-NMMA atenuou o relaxamento causado pelo sulfato de protamina em anéis sem endotélio. O L-NMMA não modificou a resposta em segmentos arteriais pulmonares sem endotélio. Além disso, na presença do L-NMMA, os segmentos vasculares pulmonares com e sem endotélio apresentaram respostas semelhantes ao sulfato de protamina. O efeito inibitório do L-NMMA na dilatação endotélio-dependente causada pela protamina pôde ser revertido pela adiçāo de L-arginina $\left(10^{-4}\right.$ M) mas não pela adição de D-arginina $\left(10^{-4} \mathrm{M}\right)$.

A heparina $(8 \mathrm{U} / \mathrm{ml}$; concentração final no banho das "organ-chambers"), não causou nenhuma alteração significante na tensão de segmentos arteriais com ou sem endotélio $(n=6$, dados não apresentados). Nas "organ-chambers" contendo heparina (8 U/ml), a adição de sulfato de protamina (40 a 400 $\mu \mathrm{g} / \mathrm{ml}$ ) causou crescente coloração turva do banho, inicialmente claro, sugerindo a formação de complexos protamina-heparina. A heparina na concentração de $8 \mathrm{U} / \mathrm{ml}$ inibiu, completamente, a resposta vasodilatadora endotélio-dependente à protamina (40 a $400 \mu \mathrm{g} / \mathrm{ml}$.Entretanto, dosagens adicionais de protamina induziram relaxamento nos segmentos de artérias pulmonares com endotélio (Gráfico 9). 
ÉVORA, P.R.B.; PEARSON, P.J.; SCHAFF, H.V. - Alguns aspectos da função endotelial em cirurgia cardiaca. Rev. Bras. Cir. Cardiovasc., 8(3): 195-214, 1993.

\section{Ensaio biológico de artérias mamárias direita e esquerda}

Após a contração do segmento de artéria coronária sem endotélio ("bioassay ring"), pela adição de prostaglandina $F_{2 \alpha}\left(2 \times 10^{-8} \mathrm{M}\right)$ ao perfusato, mudando-se o gotejamento do perfusato da linha metálica (superfusão direta) para o gotejamento do perfusato através através dos segmentos das artérias mamárias doreita e esquerda (superfusão endotelial), obteve-se um relaxamento estável do "bioassay ring" indicando uma liberação basal de EDRF (Gráfico 10). Este relaxamento, induzido pela superfusão através das artérias mamárias pôde ser prevenido pela remoção mecânica dos seus endotélios, pela adição de $\mathrm{N}^{\mathrm{G}}$-monometil-L-arginina $\left(10^{-4} \mathrm{M}\right)$ ou $\mathrm{N}^{\mathrm{G}}$-nitroL-arginina $\left(10^{-4} \mathrm{M}\right)$ ao perfusato. A adição de indometacina $\left(10^{-5} \mathrm{M}\right)$ não afetou a atividade vasodilatadora dos efluentes de ambas artérias mamárias (Gráfico 10).

Em 20 de 24 experimentos (83\%) a artéria mamária esquerda apresentou maior liberação de EDRF do que a correspondente artéria direita (Gráfico 11). Acresça-se que a vasodilatação média causada pela artéria mamária esquerda foi

GRÁFICO 10

ENSAIO BIOLÓGICO

FREQÜÊNCIA DE MAIOR LIBERAÇÃO DO EDRF/NO

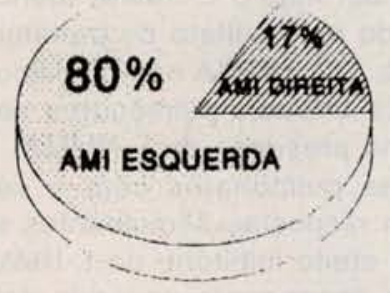

\section{LIBERACAO BASAL DE EDRF/NO}

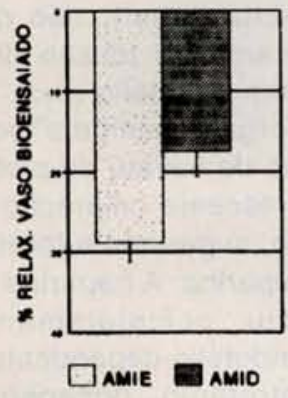

Comparação da liberação de EDRF/NO pelas artérias mamárias internas direita e esquerda. de $28.9 \pm 2.3 \%$ contra $17.4 \pm 3.1 \%$ para a mamária direita $(\mathrm{p}<0.05)$ (Gráfico 11). O maior relaxamento induzido pela artéria mamária esquerda foi independente da ordem de superfusão, ou seja, não dependeu de qual artéria foi ensaiada em primeiro lugar. Além disso, não houve nenhuma diferença, estatísticamente significante, nos níveis de pré-contrações dos "bioassays rings" anterior às superfusões de ambas as artérias. Acresça-se, ainda que as médias das áreas superficiais, medidas por planimetria assistida por computador realizada em 19 consecutivos estudos foram, respectivamente, $251.1 \pm 8.9$ e 251.6 $\pm 9.0 \mathrm{~mm}_{2}$ para as artérias direita e esquerda (média \pm erro-padrão, $\mathrm{P}=\mathrm{NS}$ ).

\section{GRÁFICO 11}

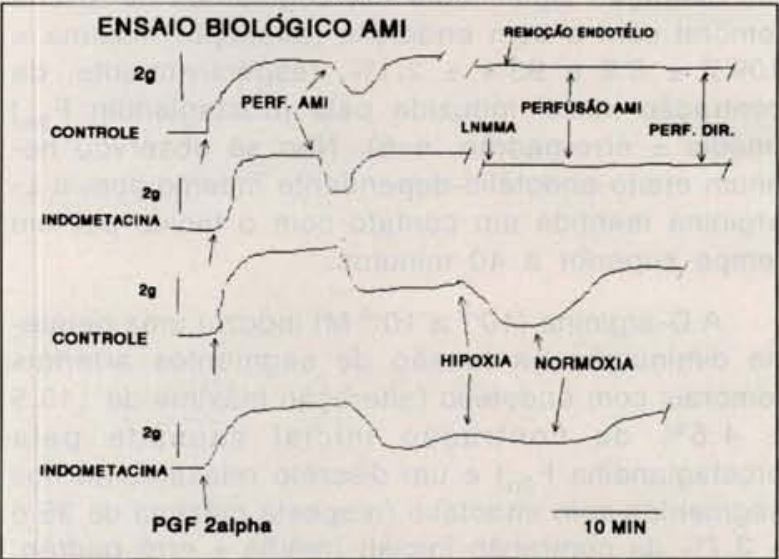

Ensaio biológico do EDRF/NO liberado pela artéria mamária esquerda (AMI) de cão (traçado original). Perfundiram-se os segmentos arteriais com $5 \mathrm{ml} \mathrm{min}^{-1}$ de soluçăo fisiológica controle. Quando se expôs o anel coronariano sem endotélio ("bioassy ring") à prostaglandina $F_{2 \alpha}$ $\left(2 \times 10^{-6} \mathrm{M}\right)$ atrvés da linha prostética direta, ele apresentou contraçắo (registro superior). Entretanto, este mesmo anel sob a ação do perfusato da AMI com endotélio, apresentou relaxamento vascular indicando uma liberação basal de EDRF/NO. Retornando-se à linha direta o "biossay ring") voltou a contrair, indicando uma remoção da ação vasodilatadora do EDF/NO. A remoção mecânica do endotélio do segmento de AMI aoliu a ação vasodilatadora do seu perfusato (registro superior). O tratamento com indometacina não alterou a atividade vasodilatadora do efluente do vaso perfundido (registro inferior). Por outro lado, o tratamento da $A M I \mathrm{com} \mathrm{N}^{G}$-nitro-L-arginina (L-NOARG) or $\mathrm{N}^{\mathrm{G}}$-monometil-L-arginina (L-NMMA) aboliu, completamente, a atividade vasodilatadora do perfusato da AMI com endotélio, porém não afetou a habilidade do "biossay ring" relaxar sob a açāo do nitroprussiato de sódio (segundo registro). Efeito da hipóxia na liberação basal de vasodilatador(es) pela artéria mamária interna (AMI) canina (traçado original). Quando se expôs o anel coronariano ("bioassy ring") à prostaglandina $\mathrm{F}_{2 \alpha}\left(2 \times 10^{-6} \mathrm{M}\right)$ através da linha metálica (linha direta), observou-se contração. A exposição ao efluente da AMI com endotélio provocou um relaxamento indicando a liberaçăo basal de EDRF/NO. Sob efeito de hipóxia ( $95 \% \mathrm{~N} 2 / 5 \% \mathrm{CO}_{2}$ ), observou-se um aumento da atividade vasodilatatora do efluente (terceiro registro). Reverteu-se, rapidamente, o aumento da atividade vasodiladora causado pela hipóxia quando se restaurou a condição de normóxia. 0 tratamento com indometacina aboliu, completamente, a acentuaçăo da vasodilatação causada pelo efluente da AMI sob as condiçōes de hipóxia (registro inferior) 


\section{Ensaio biológico de artérias mamárias e veias safenas}

A adição de prostaglandina $F_{2 \alpha}\left(2 \times 10^{-6} \mathrm{M}\right.$ ao perfusato induziu uma contração estável no "bioassay ring" coronariano. Após esta contração, alternando-se o gotejamento da linha direta para as linhas da artéria mamária ou veia safena (superfusão endotelial), obteve-se relaxamento estável do "bioassay ring" $(29.02 \pm 2,7 \%$ e $30,67 \pm 2.36 \%$ da contração inicial, média \pm êrro-padrão, $n=10$ ). Não houve nenhuma diferença estatisticamente significante na magnitude das vasodilatações causadas pelo efluentes das artérias mamárias e das veias safenas. Retornando-se à superfusão para a linha metálica direta, o relaxamento observado pelas superfusões vasculares foram, ràpidamente, revertidas com os "bioassays rings" retornando aos seus niveis de précontração. Os relaxamentos causados pelas superfusões de ambos os vasos puderam ser prevenidas pela remoção mecânica de seu endotélios $(0.0$ $\pm 0.0 \%$ para as artérias mamárias e $0.87 \pm 0,50 \%$ para as veias safenas), demonstrando uma liberação luminal de EDRF pela íntima dos vasos ensaiados.

A atividade vasodilatadora dos efluentes das artérias mamárias não foi afetada pela presença de indometacina $\left(10^{-6} \mathrm{M}\right)$ (bloqueador da ciclooxigenase) no fluido de perfusão. Esta relaxamento foi de $29.18 \pm 3.94 \%$ da contração inicial causada pela prostaglandina $F_{2 \alpha}$ (média \pm êrro-padrão), relaxamento este não diferente dos ensaios contrôles sem a presença de indometacina $(n=10, N S p<0.05)$, indicando que prostanóides endoteliais não estão envolvidos na produção dos relaxamentos produzidos nos "bioassays rings". Em contraste, a indometacina diminuiu, significantemente, a produção de vasodilatador pela veia safena perfundida, causando um relaxamento de $18.12 \pm 3.6 \%$ da contração inicial produzida pela prostaglandina $\mathrm{F}^{2 \alpha}$ (média \pm êrro-padrão, $n=10, p<0.05$ ).

A atividade vasodilatadora do efluente de ambas as artériasa mamárias e da veia safena pôde ser inibida pela adição de $N^{G}$-monometil-L-arginina ( $L$ NMMA) $\left(10^{-4} \mathrm{M}\right)$ ou de $\mathrm{N}^{\mathrm{G}}$-nitro-L-arginina ( $\mathrm{L}$ NOARG) $\left(10^{-4} \mathrm{M}\right)$ no líquido de perfusão. Entretanto, L-NMMA e L-NOARG não alteraram a habilidade do "bioassay ring" coronariano relaxar sob a ação do nitroprussiato de sódio $\left(10^{-7} \mathrm{M}\right)$.

A atividade vasodilatadora do efluente das artérias mamárias e veia safena aumentou quando os vasos foram expostos a hipóxia $\left(95 \% \mathrm{~N} / 5 \% \mathrm{CO}_{2}\right.$, $\mathrm{pO}_{2}=50 \mathrm{mmg}, \mathrm{pH}=7.4$ ) com valores respectivos de $50.66 \pm 7.68 \%$ e $68.23 \pm 7.43 \%$ da contração inicial produzida pela prostaglandina $F_{2 \alpha}$ (média \pm erropadrão, $n=10, p<0.05)$, quando comparada com os relaxamentos controles. $\mathrm{O}$ aumento da atividade vasodilatadora pela hipóxia foi, imediatamente, re- vertido com o retôrno à situação de normóxia. O aumento da atividade vasodilatadora pela hipóxia, em ambas artérias mamárias e veia safena, pode ser inibida pela adição de indometacina ao perfusato (Fig. 10). Entretanto, a produção de vasodilatação aumentada pela hipóxia não foi afetada pela presença de L-NMMA e NO-ARG $\left(10^{-4} \mathrm{M}\right)(n=3$, dados não apresentados).

Quando foram medidas as superfícies das áreas por planimetria assistida por computador, os valores para as artérias mamárias e veia safena foram, respectivamente, $3.27 \pm 0.20$ e $3.30 \pm 0.13$ $\mathrm{cm}_{2}$ (média \pm êrro-padrão, $\mathrm{P}=\mathrm{NS}$ ).

\section{COMENTÁRIOS}

\section{Função Endotelial Após Isquemia Globale Reperfusão}

Neste trabalho estudou-se um possivel mecanismo de comprometimento seletivo da liberação receptor-mediada do EDRF após isquemia global e reperfusão. Escolheu-se um modelo de isquemia global não modificada por intervenções como a cardioplegia ou a hipotermia, de tal forma a isolar os efeitos da isquemia/reperfusão. É razoável assumir que métodos protetores do miocárdio contra os efeitos da isquemia/reperfusão possam, também, reduzir lesões coronarianas endoteliais; entretanto, este fato necessita comprovação. O método experimental utilizado produz, somente, moderado gráu de comprometimento, demonstrado pelo fato de que a grande maioria dos imais pôde ser retirada de circulação extracorpórea, com certa facilidade, após o período de 45 minutos de clampeamento aórtico.

Outros investigadores têm sugerido que receptores da célula endotelial são ligados com a produção e liberação do EDRF/NO através de G-proteínas (FLAVAHAN \& VANHOUTTE ${ }^{11}$; SHIMOKAWA et alii $^{41}$ ) as quais são mediadoras de muitas vias receptores-dependentes(DOHLMAN et alii ${ }^{10}$; FREISSMUTH et alii ${ }^{12}$ ). Com base nestes dados, hipotizou-se que a disfunção de G-proteínas após isquemia cardíaca global e reperfusão possa acontecer como um mecanismo de comprometimento de relaxamento a agonistas endotélio-dependentes com resposta normal a agonistas endotélio-independentes. Se G-proteínas são necessárias para a transdução do sinal para a produção de EDRF/NO entre o receptor celular e o mecanismo de síntese, a lesão de G-proteínas induzida pela reperfusão pode comprometer a liberação de EDRF/NO receptor-mediada, sem afetar a habilidade da célula endotelial produzi-lo.

Para testar a função G-proteína na célula 
endotelial após a lesão de reperfusão usou-se o fluorêto de sódio ( $\mathrm{NaF})$, o qual ativa G-proteínas, diretamente, pela formação de fluoroaluminato complexo $\mathrm{AIF}_{4}\left(\right.$ STERNWEIS \& GILMAN $\left.{ }^{44}\right)$. Além disso, na artéria coronária canina, o $\mathrm{NaF}$ é um marcador específico para a indução de relaxamento endotéliodependente atuando em G-proteína(s) sensível à toxina pertussis (FLAVAHAN \& VANHOUTTE ${ }^{11}$; CUSHING et alii ${ }^{9}$ ). Nos experimentos controles, o $\mathrm{NaF}$ induziu relaxamento concentração-dependente em artérias coronárias con endotélio e uma discreta contração nas coronárias sem endotélio. Entretanto, após isquemia global e reperfusão, houve um significante comprometimento do relaxamento endotélio-dependente ao NaF. Este achado demonstra um comprometimento do relaxamento endotéliodependente G-proteína-mediado causado pela lesão coronariana de reperfusão. Este comprometimento foi, claramente devido a isquemia cardíaca global e reperfusão porque artérias coro-narianas de animais expostos a circulação extracorpórea sem clampeamento aórtico ou isquemia global mostraram relaxamento endotélio-dependente normal ao $\mathrm{NaF}$.

A importância destes resultados tem uma dupla significância. Primeiro, eles confirman que, após a lesão de reperfusão, a célula preserva a capacidade de sintetizar o EDRF/NO. Segundo, ambos A23187 e fosfolipase $\mathrm{C}$ induzem relaxamentos endotéliodependentes normais utilizando cálcio extracelular ou intracelular, mostrando de maneira a não deixar dúvidas, que a célula endotelial mantém a capacidade de produzir EDRF. O cálcio ionóforo A23187 atua como um transportador, e a fosfolipase C, provavelmente, forma inositol-1,4,5-trifosfato $\left(\mathrm{IP}_{3}\right)$ (BERRIGE \& IRVINE 4; LAMBERT et alii ${ }^{25}$ ). Logo, agonistas que induzem relaxamentos endotélio-dependentes através, primariamente, do transporte de cálcio ou através da liberação direta de armazenamentos intracelulares de cálcio, não apresentam alterações de seus mecanismos de ação após a lesão de reperfusão.

Considerando-se o papel dos cálcios intra e extracelulares na sintese do EDRF/NO, pode-se considerar como hipóteses pelo menos três mecanismos para o comprometimento da liberação receptor-mediada de EDRF/NO após a a lesão de reperfusão. Primeiro, receptores da superfície da célula endotelial que se ligam a compostos que induzem relaxamento endotélio-dependente podem estar lesados ou incapazes de ligar-se, eficientemente, a um agonista. Entretanto, cronicamente, após oclusão coronariana aguda, o relaxamento endotélio-dependente a alguns agonistas receptores-dependentes são normais, ao passo que aqueles relaxamentos endotélio-dependentes mediados pelas plaquetas encontram-se comprometidos
(PEARSON et alii ${ }^{35}$ ). Com base nestes dados, podese propor uma disfunção seletiva de certas populações de receptores na superfície celular. Segundo, a G-proteína que liga o receptor da célula endotelial à fosfolipase $\mathrm{C}$ pode ser disfuncional. Como a fosfolipase $\mathrm{C}$ promove a ativação da via fosfatidilinositol, pode-se inferir a importância deste mecanismo para a elevação inicial do cálcio intracelular associada com a produção do EDRF/NO (LAMBERT et alii ${ }^{25}$ ), isto pode explicar a atenuação endotélio-dependente após a reperfusão coronariana. Finalmente, a G-proteína associada com o canal de cálcio na membrana celular pode estar disfuncional, devendo-se levar em conta este fato no comprometimento do relaxamento endotélio-dependente receptores-mediados após a reperfusão coronariana. O cálcio extracelular é necessário para o relaxamento endotélio-dependente normal, e o íon fluoreto é um ativador específico de uma G-proteína associada ao canal de cálcio presente na membrana da célula endotelial. Logo, pode-se inferir que o comprometimento do relaxamento endotélio-dependente a agonistas receptores-dependentes, após a reperfusão, deve-se a uma atenuação do influxo extracelular do cálcio necessário para a produção contínua de EDRF/NO.

\section{Função Endotelial, Soluções e Hipotermia.}

\section{Solução cardioplégica cristalóide (St.Thomas)}

Estudos in vitro do endotélio utilizando cultura de células (CARPENTER et alii ${ }^{7}$; SOLBERG et alii ${ }^{43}$ ) ou métodos morfométricos (HARJULA et alii ${ }^{15}$ ) indicam que soluções cardioplégicas hipercalêmicas possam ser citotóxicas, e, existem alguns conceitos mal compreendidos de que as técnicas atuais de proteção miocárdica com cardioplegia possam induzir lesões endoteliais celulares com comprometimento dos mecanismos protetores contra o vasoespasmo e trombose intravascular.

Usando corações isolados, SALDANHA \& HEARSE 40 encontraram que a cardioplegia hipercalêmica pode causar lesão celular endotelial. Nestes experimentos, entretanto, os corações de ratos foram perfundidos por 30 minutos com solução hipercalêmica oxigenada a $100 \mathrm{mmHg}$. O planejamento deste estudo, e de outros, não isolou os efeitos do "shear stress" e da pressão durante a infusão da cardioplegia, fatores estes conhecidos como prováveis causadores de disfunção endotelial (KONTOS ${ }^{23}$ ). No presente estudo eliminaram-se estas variáveis, tratando-se os segmentos vasculares in vitro com cardioplegia hipotérmica. Os resultados deste modelo demonstram que a cardioplegia hipercalêmica não lesam o endotélio e a muscula- 
ÉVORA, P.R.B.; PEARSON, P.J.; SCHAFF, H.V. - Alguns aspectos da função endotelial em cirurgia cardiaca. Rev. Bras. Cir. Cardiovasc., 8(3): 195-214, 1993.

tura lisa vascular. Após 45 minutos de parada cardioplégica ou tratamento da artéria coronariana com cardioplegia normotérmica ou hipotérmica, os relaxamentos endotélio-dependentes produzidos pela acetilcolina ou pelo composto plaquetário ADP foram normais em artérias epicárdicas coronarianas. Em adição, o relaxamento ao fluoreto de sódio, o qual promove a liberação de EDRF/NO pela estimulação de G-proteína sensivel à toxina pertussis, também mostrou-se inalterado ao final de 45 minutos de parada cardioplégica. A habilidade da musculatura vascular contrair pela ação dos íons potássio (voltagem-dependente), ou pela ação da prostaglandina $F_{2 \alpha}$ (receptor-dependente) permanece inalterada. A habilidade de relaxar pela ação do nitroprussiato de sódio (cGMP mediada), ou pela ação do isoproterenol (cAMP mediada) não foram, também, afetadas pelo tratamento cardioplégico e pela hipotermia. Este estudo demonstra, claramente, que a solução cardioplégica cristalóide hiperpotassêmica não prejudica a função vascular de artérias coronarianas epicárdicas.

O conceito inicial relativo à lesão coronariana causada pela cardioplegia baseou-se em observações sobre o efeito da hipercalemia na reatividade vascular. A alta concentração de potássio presente nas soluções cardioplégicas podem, teoricamente, induzir a liberação de prostaglandinas vasoativas pela célula endotelial e causar lesão da célula endotelial secundária à produção de ânion superóxido. No presente trabalho encontrou-se, entretanto, que o relaxamento endotélio-dependente foi normal após a exposição à hipercalemia. Portanto, é improvável que a lesão endotelial por radicais livres ciclooxigenase-dependentes é um mecanismo fisiopatológico nas artérias coronarianas epicárdicas.

Um outro assunto controverso, relacionado com os métodos de proteção miocárdica, diz respeito aos efeitos da hipotermia na circulação coronariana. Exposição a baixas temperaturas podem comprometer a liberação basal e estimulada do EDRF/NO (BODELSSON et alii ${ }^{5}$ ). O presente experimento mostrou que este é um fenômeno ràpidamente reversível com nenhum efeito sustentado. Isto concorda com estudos de culturas de células endoteliais humanas, nos quais as alterações estruturais induzidas pela hipotermia $\left(10^{\circ} \mathrm{C}\right.$ ou $20^{\circ} \mathrm{C}$ por 1 ou 5 horas) são rápida e quase completamente revertidas após reaquecimento (SOLBERG et alii ${ }^{43}$ ).

Vários grupos têm demonstrado uma profunda e generalizada evidência histológica de lesão endotelial após infusão de cardioplegia cristalóide (HARJULA et alii ${ }^{15}$; MOLINA et alii ${ }^{32}$; CHIAVARELLI et alii ${ }^{8}$ ), mas os resultados destes trabalhos podem ser atribuídos pelos efeitos da pressão e "shear stress" no endotélio vascular. Altas pressões de infusão podem lesar o endotélio coronariano (MOLINA et alii ${ }^{32}$ ). Deve-se lembrar que o controle da pressão de infusão não garante "shear stress" normal nas artérias coronarianas epicárdicas. Mas, parece provável que a lesão da célula endotelial pela infusão de cardioplegia é, ao menos em parte, uma expressão da lesão induzida por "shear stress" e barotrauma. Esta hipótese é concordante com o achado de que fluidos com diferentes viscosidades induzem diferentes graus de lesão endotelial durante a infusão coronariana (Harjula et alii ${ }^{15}$ ). No entretanto, demonstrou-se na presente investigação, que infusões com pressões controladas (entre 90 e $120 \mathrm{mmHg}$ de pressão na raíz da aorta), que a disfunção do endotélio de coronárias epicárdicas devido a barotrauma e "shear stress" é mínima.

Em conclusão, cardioplegia cristalóide moderadamente hipercalêmica não altera a produção endotelial de EDRF/NO, e nem a função da musculatura lisa vascular de artérias coronarianas epicárdicas. Além disso, a hipotermia não induz alterações permanentes da função endotelial ou da musculatura lisa vascular. Pode-se considerar estudos futuros sobre os efeitos da pressão de infusão da cardioplegia e o resultante "shear stress" e efeitos pressóricos sobre o endotélio coronariano.

\section{Solução da Universidade de Winscosin (Solução UW)}

Demonstrou-se, neste trabalho, que a a solução da Universidade de Winscosin (solução UW) não altera, irreversivelmente, a função da musculatura lisa de artérias coronárias epicárdicas, ou compromete a síntese do EDRF/NO pelo seu endotélio. Logo, do ponto de vista dos seus efeitos nas artérias coronárias, a solução UW parece segura como uma solução preservativa para transplantes cardíacos.

Existem justificados conceitos de que as soluções para preservação possam causar lesão da íntima vascular e comprometer a função cardíaca após transplante cardiaco. Sería desejável, precocemente após transplante cardíaco, a presença de uma íntima vascular com seu endotélio normal, exercendo seus efeitos vasodilatadores e anti-trombóticos na circulação coronariana, esperando-se que, tardiamente, ela possa inibir a aterogênese. Este estudo demonstrou que a preservação com a solução UW não compromete a produção de EDRF/NO pelo endotélio de artérias coronarianas epicárdicas do cão.

A respeito dos elevados níveis de potássio (140 $\mathrm{mEq} / \mathrm{L}$ ) existentes na solução UW, valem as considerações feitas para a solução cardioplégica. Apesar de níveis acima de $100 \mathrm{mEq} / \mathrm{L}$, os efeitos da hipercalemia na reatividade vascular (hiperpolarização celular e aumento do tono vascular mediado por prostanóides), são revertidos, com 
ÉVORA, P.R.B.; PEARSON, P.J.; SCHAFF, H.V. - Alguns aspectos da função endotelial em cirurgia cardiaca. Rev. Bras. Cir. Cardiovasc., 8(3): 195-214, 1993.

relativa rapidez, após a lavagem da solução UW. A soluçāo UW normotérmica induziu vasoconstrição transitória de artérias coronarianas epicárdicas. Entretanto, isto ocorreu na presença de indometacina e foi independente da presença ou não de endotélio. Logo, a constrição observada teve como causa mais provável a despolarização da musculatura lisa vascular pelo potássio da solução UW. Íons potássio são potentes constritores da musculatura lisa vascular in vitro. Solução UW gelada, não induziu vasoconstrição de segmentos coronarianos epicárdicos porque a hipotermia, por si própria, é uma antagonista da contração da musculatura lisa.

O fato de que a solução UW provoca vasoconstrição potássio-induzida de artérias coronarianas epicárdicas tem implicações quanto às propriedades de certas soluções usadas para preservação cardíaca. Alguns investigadores têm empregado perfusão con fluxo constante para a avaliação dos efeitos vasculares das soluções de preservação cardíaca (HARJULA et alii 15: SALDANHA \& HEARSE 40; MANKAD et alii ${ }^{29}$ ). Como o presente experimento e o estudo da solução cristalóide cardiopégica mostraram, a infusão da solução UW por si só pode aumentar o tono vascular e, secundariamente, aumentar a pressão e "shear stress" no circuito de fluxo constante. Altas pressões induzem lesão da célula endotelial coronariana e de artérias cerebrais (KONTOS \& WEI ${ }^{23}$ ). Portanto, com base nestas observações, pode-se concluir, errôneamente, que a solução UW é tóxica para o endotélio, quando - mecanismo provável pode ser o barotrauma do circuito de perfusão constante. Por outro lado, os resultados obtidos na presente investigação podem levar a interpretações de que a solução UW não elesiva porque a hipotermia, antagonizando a constrição da musculatura lisa, previne a vasoconstrição causada pelo aumento da pressão de infusão (barotrauma). Esta interpretação podería, errôneamente, levar à conclusão de que a solução UW podería ser tóxica em coraçōes normotérmicos metabolicamente ativos. Como no estudo da solução cardioplégica cristalóide, os prováveis efeitos da hipotermia foram, completamente, revertidos pelo reaquecimento.

Em conclusão, a solução UW não afeta a produção endotelial de EDRF/NO e nem a função da musculatura lisa vascular de artérias coronarianas epicárdicas. A hipotermia, por si só, também não causa comprometimento irreversível destas funções. Estes achados são compativeis com estudos prévios que suportam a conclusão de que a solução UW é segura para a preservação cardíaca. Futuros estudos que venham a estudar os efeitos de soluções para preservação de órgãos devem considerar os confusos efeitos da vasoconstrição induzida pelo potássio durante a infusão de soluções hiper- calêmicas e os efeitos resultantes do "shear stress" e da pressão de infusão no endotélio vascular.

\section{Função endotelial, protamina e protamina/heparina}

Por mais de 50 anos, o sulfato de protamina tem-se reconhecido que o sulfato de protamina induz uma profunda hipotensão transitória quando infundida em animais de experimentação (JAQUES ${ }^{19}$ ). Entretanto, até o desenvolvimento da cirurgia cardíaca, a hipotensão induzida pela protamina foi um fenômeno experimental de pequena relevância clínica. Com prática usual, o sulfato de protamina é amplamente utilizado para reverter o efeito anticoagulante da heparina após circulação extracorpórea e hemodiálise, sendo que reações ao seu uso posem levar a hipotensão sistêmica, hipertensão pulmonar e choque. Algumas destas reações adversas são, especialmente, perigosas no período imediatamente após a circulação extracorpórea quando volumes intravasculares e a função cardíaca podem estar comprometidos.

O sulfato de protamina pode, também, causar alterações hemodinâmicas devido a reações anafiláticas (LOWENSTEIN \& ZAPOL ${ }^{27}$; WHITMAN et alii ${ }^{48}$ ). A conhecida classificação de Horrow (HORROW ${ }^{17}$ ) classifica as reações à protamina em tres separadas e distintas entidades: 1) Hipotensão sistêmica como uma reação comum; 2) reações anafilactóides; 3) vasoconstrição pulmonar catastrófica. O efeito hipotensor da protamina tem sido demonstrado em muitos animais (MARIN-NETO et alii ${ }^{30}$; WAKEFIELD et alii ${ }^{47}$ ) e em estudos humanos (KIRKLIN et alii 22; PROCACCINI et alii 36; WAKEFIELD et alii ${ }^{46}$ ). Entretanto o mecanismo preciso desta hipotensão é desconhecido, parecendo que a protamina diminui a resistência vascular periférica (KIRKLIN et alii ${ }^{22}$ ) mais do que deprime a função miocárdica (HINES \& BARASH ${ }^{16}$ ).

Dados recentes sugerem que a protamina causa vasodilatação coronariana (WAKEFIELD et alii ${ }^{46}$ ). Nestes estudos, a protamina $(250 \mathrm{ug} / \mathrm{ml})$ causou um significante aumento no fluxo coronariano durante perfusão em coração isolado de coelho. Este aumento foi transitório quando a protamina foi infundida juntamente com heparina, e, mantida quando infundiu-se apenas protamina.

No presente estudo, concluíu-se que a protamina causa uma diminuição da resistência vascular pelo estímulo da liberação de EDRF/NO. A prostaciclina não pode ser implicada como mediadora da dilatação endotélio-dependente causada pela protamina não foi afetado pela presença de indometacina.

A protamina pode estimular a produção de EDRF/NO pelo aumento do substrato L-arginina e/ 
ÉVORA, P.R.B.; PEARSON, P.J.; SCHAFF, H.V. - Alguns aspectos da funçăo endotelial em cirurgia cardíaca. Rev. Bras. Cir. Cardiovasc., 8(3): 195-214, 1993.

ou liberação por estimulação receptor-mediada. Hipotizou-se, inicialmente, que o sulfato de protamina, o qual é rico em L-arginina (ANDO et alii ${ }^{1}$ ), estimula a produção de EDRF/NO por fornecer Larginina exógena como substrato. Entretanto, dois achados deste experimento argumentam contra esta hipótese. Primeiro, a adição de altas concentrações de L-arginina ao banho orgânico dos anéis vasculares não produziu relaxamento endotélio-dependente. Por outro lado, observa-se este tipo de relaxamento pela ação da poli-L-arginina (um polipeptídeo de alto peso molecular contendo L-arginina), sendo que este efeito não é bloqueado pelo LNMMA e, parece ser mediado por um EDRF independente do óxido nítrico (PEARSON et alii ${ }^{34}$ ).

Segundo, a protamina induz relaxamento endotélio-independente na presença de excessivas quantidades de heparina. O sulfato de heparina, o qual é polianiônico, forma forte ligações com a policatiônica protamina. No presente experimento, a formação de complexos heparina-protamina foi caracterizada oela turvação do banho orgânico, inicialmente claro, das "organ chambers" (O'REILLY ${ }^{33}$ ). Mesmo na presença de heparina e, com a formação de complexos heparina-protamina, a protamina produziu relaxamentos endotélio-dependentes, comparáveis com os relaxamentos induzidos sem a presença da heparina. Isto argumenta contra a hipótese da L-arginina como precursor da liberação de EDRF/NO pela protamina, pois espera-se que o grande complexo heparina-protamina não entre na célula endotelial.

Com base nestes argumentos, hipotizou-se que a protamina, livre ou ligada à heparina, atua em receptores endoteliais para estimular a produção de EDRF/NO, que pode constituir-se no mecanismo da hipotensão sistêmica após infusão de protamina. Acresça-se que compostos como o L-NMMA podem ser infundidos concomitantemente com a protamina para inibir-se a vasodilatação endotélio-dependente, causada pela heparina, como tem sido feito com outros vasodilatadores endotélio-dependentes no homem (VALLANCE et alii ${ }^{45}$ ).

A seqüela idiosincrática da infusão de protamina na circulação pulmonar tem levado muitos investigadores a considerar a protamina como um vasoconstritor pulmonar. Entretanto, o presente estudo sugere que os efeitos vasoconstritores da protamina possam ser secundários, porque o efeito direto da protamina é o de vasodilatação devida à liberação de EDRF/NO.

No presente experimento, a vasodilatação mediada pela protamina em segmentos isolados de artéria pulmonar é, claramente, devida à liberação estimulada de EDRF/NO. Confirmou-se este fato pela inibição da vasodilatação pelo $n_{G}$-monometil-L- arginina (L-NMMA), o qual é um inibidor competitivo da síntese de óxido nítrico a partir do aminoácido básico L-arginina (REES et alii ${ }^{38}$ ). Acresça-se que se demonstrou a especificidade do L-NMMA para o metabolismo da L-arginina pela reversibilidade da inibição competitiva pela adição de L-arginina exógena mas não de D-arginina.

O mecanismo pelo qual a protamina induz a liberação de EDRF/NO permanece um enigma. A protamina é rica no aminoácido L-arginina (Ando et alii ${ }^{1}$ ), o precursor fisiológico do óxido nítrico; entretanto a adição exógena de L-arginina não induz relaxamento endotélio-dependente in vitro. Isto sugere que a célula endotelial tem precursor suficiente ou uma via preservadora de L-arginina, de tal forma que a avaliabilidade do substrato não é um fator limitante da produção de óxido nítrico. Esta hipótese é suportada pelo achado de que a protamina não pôde induzir a liberação de EDRF/NO quando sob a forma de complexo protaminaheparina. Este complexo altera, presumivelmente, a ligação da protamina à célula endotelial por competição esterásica ou alteração de carga elétrica. Neste aspecto a reatividade da circulação pulmonar foi diferente das respostas obtidas nas circulações coronariana renal e femoral, onde a heparina não interferiu nos relaxamentos endotélio-dependentes causados pela protamina.

A estimulação de EDRF/NO pela protamina pode ser um efeito compensador da vasoconstrição pulmonar mediada por tromboxane, a qual é característica da vasoconstrição pulmonar catastrófica que se segue à infusão de protamina. É possível que certos indivíduos percam a habilidade de liberar EDRF/NO na circulação pulmonar por lesões secundárias pré-existentes ou por lesão de reperfusão do endotélio pulmonar. Se a produção de EDRF/NO na circulação pulmonar encontra-se prejudicada, os efeitos constritores de autacóides endógenos podem, em oposição, expressar-se. É possível, também, que a lesão do endotélio vascular possa mudar o efeito vasodilatador da protamina para um efeito vasoconstritor sôbre a musculatura lisa vascular.

Em conclusão, o sulfato de protamina estimula a liberação de EDRF/NO pelo endotélio arterial pulmonar. Este efeito pode ser inibido por concentrações comparáveis de heparina. Espera-se que a liberação de EDRF/NO pelo sulfato de protamina diminua a resistência vascular pulmonar e, possa contrapor os efeitos vasoconstritores de autacóides endógenos na circulação pulmonar.

\section{Ensaio biológico das artérias mamárias direita e esquerda}

A maior liberação de EDRF/NO pelos vasos 
ÉVORA, P.R.B.; PEARSON, P.J.; SCHAFF, H.V. - Alguns aspectos da função endotelial em cirurgia cardiaca. Rev. Bras. Cir. Cardiovasc., 8(3): 195-214, 1993.

arteriais pode explicar, em parte, a sua superior patência quando comparadas com veias utilizadas para revascularização do miocárdio (LUSCHER et $a^{a}{ }^{28}$ ). O endotélio da artéria mamária interna (AMI) produz, também, prostaciclina (AARNIO et alii; JOHNS et alii ${ }^{20}$ ). Entretanto, a quantidade de prostaciclina produzida pelo endotélio da AMI sob condições basais não é significante o suficiente para induzir relaxamento da musculatura lisa de artérias coronarianas epicárdicas. Acresça-se o fato de que a prostaciclina, quando comparada com o EDRF/ NO, é, relativamente, um fraco vasodilatador coronariano (SHIMOKAWA et alii ${ }^{41}$ )

Uma evidência adicional de que o EDRF/NO liberado pela $\mathrm{AMI}$ é óxido nítrico reside no fato de que a oxihemoglobina bloqueia a vasodilatação endotélio-dependente. A oxihemoglobina "scavenges" o radical NO e é um inibidor seletivo da vasodilatação devida ao óxido nítrico (RUBANYI et alii ${ }^{39}$; MARTIN et alii ${ }^{31}$ ). Além disso, o presente estudo mostrou que todo o óxido nítrico é gerado pela íntima vascular, pois a remoção do endotélio inibiu, completamente, a vasodilatação endotéliodependente tanto nos estudos em "organ chambers", como nos ensaios biológicos. Como os prostanóides, - EDRF/NO é liberado, bidirecionalmente, pelo endotélio. O EDRF/NO extraluminal atua na musculatura lisa vascular subjacente, e a o EDRF/NO intraluminal é liberado para o sangue. A liberação extraluminal de EDRF/NO, precocemente, causa vasodilatação da ponte de AMI. Pelo fato de que o óxido nítrico inibe a mitogênese e a proliferação de músculo liso (GARG \& HASSID ${ }^{13}$ ), a produção extraluminal pode, a longo prazo, prevenir a ateroesclerose. Prévios estudos in vitro da função de pontes de AMIs, utilizando "organ chambers" que, primàriamente, medem o efeito do EDRF/NO extraluminal durante a estimulação com vários agonistas (LUSCHER et alii ${ }^{28}$ ). O sistema de ensaio biológico usado neste estudo documentou, pela primeira vez, a liberação de EDRF/NO de AMI perfundida sob condições basais (não estimulada). No período precoce após a revascularização do miocárdio, a produção intraluminal de EDRF/NO pode ter várias ações importantes. A liberação intraluminal de EDRF/NO previne a adesividade plaquetária à parede vascular (RADOMSKI et alii ${ }^{37}$ ). Como o vasoespasmo é diretamente relacionado com a deposição plaquetária (LAM et alii ${ }^{24}$ ), esta ação pode, secundàriamente, diminuir o tono vascular. Acresça-se que esta liberação intraluminal inibe a agregação e promove a desagregação plaquetária (RADOMSKI et alii ${ }^{37}$ ) através de um mecanismo dependente do GMP-cíclico. Finalmente, a liberação intraluminal de EDRF/NO pode causar vasodilatação anterógrada de leitos arteriais (KELM \& SCHRADER ${ }^{21}$ ). No presente experimento demonstrou-se esta atividade vasodilatadora pelo acentua- do relaxamento no anel coronariano bioensaiado pelo efluente dos segmentos de AMls perfundidas. Porque o aumento do fluxo sanguíneo aumenta a liberação luminal de EDRF/NO, espera-se que esta ação seja mais acentuada nas condições de alto fluxo in vivo (RUBANYI et alii ${ }^{39}$ ).

Um resultado inesperado deste experimento foi a demonstração de que a AMI esquerda libera mais EDRF/NO intraluminal do que a AMI direita. Este fato não pode ser atribuído a diferentes tamanhos das artérias, porque as medidas de sua áreas de superfície foram iguais. Pode-se especular que as diferentes origens embriológicas das AMls possa ter importância nesta diferença de comportamento fisiológico na liberação do EDRF/NO. A AMI direita tem sua origem embriológica no quarto arco aórtico, ao passo que a $\mathrm{AMI}$ esquerda origina-se da sétima artéria intersegmentar. Na prática clínica, a produção intraluminal aumentada de EDRF/NO pela AMI esquerda pode ser um fator, que somada a considerações técnico-cirúrgicas, possa explicar a sua maior patência a longo prazo, em revascularizaçōes miocárdicas, quando comparadas com os resultados obtidos com a AMI direita (HUDLESTON et alii ${ }^{18}$ ).

\section{Ensaio biológico de artérias mamárias e veias safenas}

Este é o primeiro estudo a demonstrar a liberação luminal de EDRF/NO plos enxêrtos de veia safena. A produção de vasodilatador pelos dois tipos de vasos foi em quantidades suficientes para induzir a relaxação da musculatura lisa da artéria coronária utilizada como detector tissular. Evidenciou-se esta produção endotelial de vasodilatador pela ausência de relaxamento induzido pelo efluente de vasos os quais tiveram o seu endotélio removido. Observou-se, nos vasos com endotélio, uma atividade vasodilatadora constante sem a necessidade da admnistração de um antagonista para a promoção de sua liberação. Logo, mesmo na ausência de uma interação droga-receptor, as AMls e as veias safenas exibiram uma significante liberação basal de EDRF/NO.

$\mathrm{Na}$ AMI perfundida, a atividade vasodilatadora do efluente não foi inibida pelo bloqueio da ciclooxigenase. Isto suporta a hipótese de que a vasodilatação produzida pela AMI não é pela liberação de prostaciclina. Entretanto, a admnistração de L-NMMA ou NO-ARG, os dois inibidores competitivos da síntese de óxido nítrico, inibiu, completamente, o relaxamento endotélio-dependente causado pelo efluente da AMI perfundida. Com base nestas obsevações, concluiu-se que o vasodilatador liberado pelo endotélio na luz da AMI perfundida é o óxido nítrico ("endothelium-derived nitric oxide" - EDNO). 
Confirmou-se a especificidade do L-NMMA e do NOARG para o endotélio da AMI e a ausência de efeito no tecido detector ("coronary bioassay ring"), pelo fato de que estes compostos não antagonizaram a vasodilatação causada pelo nitroprussiato de sódio na musculatura lisa vascular.

O bloqueio da ciclo-oxigenase inibiu, significantemente, a produção de vasodilatado pela veia safena. Uma vez que a prostaciclina é o prostanóide vasodilatador primário produzido pelo endotélio (SHIMOKAWA et alii ${ }^{41}$ ), isto indica que a prostaciclina tem uma contribuição sugnificante para a atividade vasodilatadora do efluente da veia safena. Entretanto, o óxido nítrico também tem o seu papel, uma vez que seus inibidores inibiram, completamente, a atividade vasodilatadora do efluente da veia safena.

Pode-se explicar o dado, aparentemente paradoxal, de que o L-NMMA ou do NO-ARG em associação ou não com a indometacina bloqueia a atividade vasodilatadora da veia safena perfundida (em oposição a um bloqueio parcial que sería de se esperar se a prostaciclina fosse responsável, em parte, pela vasodilatação) por, pelo menos, dois mecanismos. Primeiro, por um sinergismo entre a prostaciclina e o EDRF/NO, além do fato de que a prostaciclina quando comparada com o EDRF/NO é, relativamente, um fraco vasodilatador da musculatura lisa de artérias coronárias epicárdicas, tendo o seu efeito exacerbado por este (SHIMOKAWA et alii ${ }^{41}$ ). Acresca-se que concentrações subliminares de óxido nítrico também exacerbam a atividade inibidora da prostaciclina na agregação plaquetária. Logo, é possível que este sinergismo seja importante para a atividade vasodilatadora do endotélio de veias safenas. Segundo, é possível, também, que a prostaciclina derivada localmente pelo endotélio venoso possa estimular a liberação de EDRF/NO. $\mathrm{Em}$ artérias epicárdicas porcinas tem-se demonstrado que a prostaciclina promove vasodilatação pela estimulação da liberação de EDRF/NO (SHIMOKAWA et alii ${ }^{41}$ ). Logo, bloqueando-se a ciclooxigenase em veias safenas, pode-se diminuir a produção de EDRF/NO.

Tanto na AMI, como na veia safena, a hipóxia aumentou a quantidade de vasodilatador liberada pelos vasos perfundidos. Este aumento foi bloqueado pela indometacina mas não pelo L-NMMA ou
NO-ARG, sugerindo que a hipóxia estimula a produção de um prostanóide pelo endotélio que, muito provavelmente, possa ser a prostaciclina. Condizentes com esta hipótese são os dados de que a hipóxia estimula a produção de prostaciclina em artérias femorais caninas perfundidas (BUSSE et $a^{16}$ ) e pelo tecido pulmonar canino in vitro (HAMASAKI et alii ${ }^{14}$ ).

No presente experimento, mostrou-se que o efluente de AMls e veias safenas perfundidas produziram relaxamentos comparáveis. Este dado diverge de estudos prévios os quais demonstraram um maior relaxamento de AMls quando comparadas com veias safenas (LUSCHER et alii 28; YANG et alii ${ }^{49}$ ). Entretanto, examinou-se, nestes experimentos, a produção estimulada por drogas, não se realizando ensaios biológicos da liberação basal de EDRF/NO. Acresça-se que a liberação basal é, provavelmente, mais importante como un determinante do tono vascular e do calibre do vaso sanguíneo (BENYO et alii ${ }^{3}$ ). Além disso, diferente do presente experimento em que os vasos foram, dissecados com cuidado e, imediatamente, utilizados para experimentos no laboratório, os experimentos usando tecido humano foram obtidos na sala cirúrgica e estocados en solução fisiológica salina até o início do estudo. Os efeitos deste tipo de manipulação na reatividade vascular normal e produção de prostanóides pode ser subestimada.

Concordando com prévios estudos, encontrouse que a $\mathrm{AMI}$, aparentemente, libera uma maior quantidade de óxido nítrico do que a veia safena. Logo, enquanto o efluente da AMI e veia safena produziram relaxamentos comparáveis, a atividade vasodilatadora da AMI, como um todo, pode ser atribuída ao EDRF/NO. Como o EDRF/NO previne a adesão plaquetária à parede vascular em adição à inibição ao processo celular que leva à aterosclerose (GARG \& HASSID ${ }^{13}$ ) (duas propriedades não divididas com a prostaciclina) isto pode estar ter relação com a relativa refratariedade das pontes de AMI à trombose e aterosclerose (LOOP et alii ${ }^{26}$ ). Uma vez que o EDRF/NO é, relativamente, um vasodilatador mais potente do que a prostaciclina (SHIMOKAWA et alii ${ }^{42}$ ). pode-se pensar na possibilidade de usar a revascularização do miocárdio como fonte de nitrovasodilatador endógeno em casos de angina instável resistente a tratamento clínico. 
ÉVORA, P.R.B.; PEARSON, P.J.; SCHAFF, H.V. - Alguns aspectos da função endotelial em cirurgia cardiaca. Rev. Bras. Cir. Cardiovasc., 8(3): 195-214, 1993.

\section{RBCCV 44205-215}

ÉVORA, P.R.B.; PEARSON, P.J.; SCHAFF, H.V. - Some aspects of the enothelial function in cardiac surgery. Rev. Bras. Cir. Cardiovasc., 8(3): 195-214, 1993.

ABSTRACT: This study shows some aspects of endothelial function closely related with cardiac surgery: 1) Following global myocardial ischemia and reperfusion, the coronary endothelium has an impaired ability to express endothelium-dependent vasodilation to the receptor-dependent agonists while endothelium-dependent relaxation to the receptor-independent $A 23187$ and phospholipase $C$ is unaltered. The relaxation to sodium fluoride, which acts on a pertussis toxin-sensitive G-protein is impaired. These experiments indicate that impaired receptor-mediated production of EDRF/NO following reperfusion injury could be due to G-protein dysfunction in the pathway which links endothelial cell receptors to the pathway of EDRF/NO synthesis; 2 ) Forty-five minutes of cardioplegic arrest of the canine heart does not alter the production EDRF/NO in the epicardial coronary artery. Similar experiments support the concept that UW solution is safe for cardiac preservation during heart transplantation; 3 ) In coronary, renal, femoral and pulmonary arterial segments, protamine induced endothelium-dependent vasodilation mediated by the stimulated release of EDRF/NO. In the pulmonary circulation, differently of the coronary, renal and femoral arteries, protamine-induced endotheliumdependent vasodilation could be inhibited by comparable amounts of heparin, and this effect was overcome by adding additional protamine; 4 ) In $83 \%$ of the superfusion experiments, effluent from the left IMA induced greater relaxation of the bioassay ring than did the right IMA due to the basal release of EDRF/NO. Because EDRF/NO induces vasodilation and also inhibits platelet adhesion, platelet aggregation, and atherogenesis, luminal release of EDRF/NO by the IMA could contribute to superior results when the artery is used in bypass grafting. Upon exposure of the grafts to hypoxia, the vasodilator activity of effluent from both IMA and saphenous vein grafts was augmented.This hypoxic augmentation could be inhibited by indomethacin treatment and the relaxation was quickly reversed with return to normoxia.

DESCRIPTORS: vascular endothelium, cardiac surgery; nitric oxide, endothelium-derived relaxing factor; EDRF.

\section{REFERÊNCIAS BIBLIOGRÁFICAS}

1 ANDO, T.; YAMASAKI, M.; SUZUKI, K. - Protamines. In: Kleinzeller A, Springer GF, Wittmann HG, (eds.) Molecular biology, biochemistry and biophysics. Berlin, Springer-Verlag, 1973.

2 AARNIO, P. T.; HARJULA, A. L.; VIINIKKA, L.; MERIKALLIO, E. M. ; MATTILA, S. P. - Prostacyclin production in free verses native IMA grafts. Ann Thorac. Surg., 45:390-392, 1988.

BENYO, Z.; KISS, G.; SZABO, C.; CSAKI, C.; KOVACH, A. G. B. - Importance of basal nitric oxide synthesis in regulation of myocardial blood flow. Cardiovasc. Res., 25:700-703, 1991.

BERRIDGE, M. J. \& IRVINE, R. F. - Inositol triphosphate, a novel second messenger in cellular signal transduction. Nature, 312:315-321, 1984.

BODELSSON, M.; ARNEKLO-NOBIN, B.; TORNEBRANDT, K. - Cooling augments contractile response to 5-hydroxytryptamine via an endothelium-dependent mechanism. Blood Vessels, 26:347-359, 1989.

BUSSE, R.; POHL, U.; FOSTERMANN, U.; BASSENGE, E. - Endothelium-dependent modulation of arterial smooth muscle tone and $\mathrm{PGI}_{2}$-release: pulsatile verses steady flow. In: POHL, U; FOSTERMANN, U; BUSSE, R; BASSENGE, E; SCHROR, E; (eds.) Prostaglandins and Other Eicosanoids in the Cardiovascular System, 2nd International Symposium 2. Basel, Karger, 1984. p. $553-558$.

7 CARPENTER, S.; MURAWSKY, M.; CARPENTER, A. Cytotoxicity of cardioplegic solutions: evaluation by tissue culture. Circulation, 64(Suppl. 2):90-95, 1981.

8 CHIAVARELLI, R.; MACCHIARELLI, G.; FAMILIARI, G.; CHIAVARELLI, M.; MACCHIARELLI, A.; DEL BASSO, P.; MARINO, B.; MOTTA, P. M. - Ultrastructural changes of coronary artery endothelium induced by cardioplegic solutions. Thorac. Cardiovasc. Surgeon, 37:151-157, 1989.

9 CUSHING, D. J.; SABOUNI, M. H.; BROWN, G. L.; MUSTAFA, S. J. - Fluoride produces endotheliumdependent relaxation and endothelium-independent contraction in coronary artery. J. Pharmacol. Exp. Therap., 254:28-32, 1990.

10 DOHLMAN, H. G.; CARON, M. G.; LEFKOWITZ, R. J. - A family of receptors coupled to guanine regulatory proteins. Biochemistry, 26:2657-2664, 1987.

11 Flavahan, N. A. \& VANhoutte, P. M. - Pertussis toxin inhibits endothelium-dependent relaxations 
ÉVORA, P.R.B.; PEARSON, P.J.; SCHAFF, H.V. - Alguns aspectos da função endotelial em cirurgia cardiaca. Rev. Bras. Cir. Cardiovasc., 8(3): 195-214, 1993.

evoked by fluoride. Eur. J. Pharmacol., 178:121124,1990

12 FREISSMUTH, M.; CASEY, P. J.; GILMAN, A. G. - G proteins control diverse pathways of transmembrane signaling. FASEB J., 3:2125-2131, 1989.

13 GARG, U. C. \& HASSID, A. - Nitric oxide-generating vasodilators and 8 -bromo-cyclic guanosine monophosphate inhibit mitogenesis and proliferation of cultured rat vascular smooth muscle cells. J. Clin. Invest., 83:1774-1777, 1989.

14 HAMASAKI, Y.; TAI, H.; SAID, S. I. - Hypoxia stimulates prostacyclin generation by dog lung in vitro. Prostagland, Leukotri. Med., 8:311-316, 1982.

15 HARJULA, A.; MATTILA, S.; MYLLARNIEMI, H.; MATTILA, I.; MATTILA, P.; SALMENPERA, M.; MERIKALLIO, E. Effects of synthetic blood and crystalloid cardioplegia solutions on coronary endothelium: an experimental scanning electron microscopic study. J. Surg. Res., 39:405-412, 1985.

16 HINES, R. L. \& BARASH, P. G. - Protamine: Does it alter right ventricular function? Anesth Analg 65:1271-1274, 1986.

17 HORROW, J.C. Protamine: A review of its toxicity. Anesth. Analg., 64:348-361, 1985.

18 HUDLESTON, C. B,; STONEY, W. S.; ALFORD Jr., W. C. - Internal mammary artery grafts: technical factors influencing patency. Ann. Thorac. Surg., 42:543549,1986

19 JAQUES, L. B. - A study of the toxicity of the protamine salmine. Br. J. Pharmacol., 4:135-144, 1949.

20 JOHNS, R. A.; PEACH, M. J.; FLANAGAN, T.; KRON, I. L. - Probing of the canine internal mammary artery damages endothelium and impairs vasodilation resulting from prostacyclin and endothelium-derived relaxing factor. J. Thorac. Cardiovasc. Surg., 97: 252-258, 1989.

21 KELM, M. \& SCHRADER, J. - Control of coronary vascular tone by nitric oxide. Circ. Res., 66:1561-1575, 1990.

22 KIRKLIN, J.K.; CHENOWETH, D. E.; NAFTEL, D. C.; BLACKSTONE, E. H.; KIRKLIN, J. W.; BITRAN, D. D.; CURD, J. G.; REVER, J. G.; SAMUELSON, P. N. - Effects of protamine administration after cardiopulmonary bypass on complement, blood elements, and hemodynamic state. Ann. Thorac. Surg. 41:193-199, 1986.

23 KONTOS, H. A.; WEI, E. P. - Reversal of acetylcholineinduced cerebral vasodilation in acute hypertension. Microvasc. Res., 29:231-232, 1985.

24 LAM, J. Y. T..; CHESEBRO, J. H.; STEELE, P.; BADIMON, L.; FUSTER, V. - Is vasospasm related to platelet deposition? Relationship in a porcine

preparation of arterial injury in vivo. Circulation, 75:243-248, 1987.

25

LAMBERT, T. L.; KENT, R. S.; WHORTON, R. Bradykinin stimulation of inositol polyphosphate production in porcine aorta endothelial cells. J. Biol. Chem., 261:15288-15239, 1986.

LOOP, F. D.; LYTLE, B. W.; COSGROVE, D. M. - Influence of the internal mammary artery graft on 10 year survival and other cardiac events. N. Engl. J. Med., 314:50-51, 1986.

27 LOWENSTEIN, E.; ZAPOL, W. M. - Protamine reactions, explosive mediator release, and pulmonary vasoconstriction. Anesthesiology 73:373-375, 1990.

LUSCHER, T. F.; DIEDERICH, D.; SIEBENMANN, R. Difference between endothelium-dependent relaxation in arterial and in venous coronary bypass grafts. $\mathrm{N}$. Engl. J. Med., 319:462-467, 1988.

MANKAD, P. S.; CHESTER, A. H.; YACOUB, M. H. Role of potassium concentration in cardioplegic solutions in mediating endothelial damage. Ann. Thorac. Surg., 51:89-93, 1991.

30 MARIN-NETO, J. A.; SYKES, M. K.; MARIN, J. L. B.; ORCHARD, C.; CHAKRABARTI, M. K.; - Effect of heparin and protamine on left ventricular performance in the dog. Cardiovasc. Res., 13:254-259, 1979.

31 MARTIN. W.; VILLANI, G. M.; JOTHIANANDAN, D.; FURCHGOTT, R. F. - Selective blockade of endothelium-dependent and glycerol trinitrate-induced relaxation by hemoglobin and by methylene blue in the rabbit aorta. J. Pharmac. Exp. Ther., 232:708716,1985

32 MOLINA, J. E.; GALLIANI, C. A.; EINZIG, S.; BIANCO, R.; RASMUSSEN, T.; CLACK, R. - Physical and mechanical effects of cardioplegic injection on flow distribution and myocardial damage in hearts with normal coronary arteries. J. Thorac. Cardiovasc. Surg., 97:870-877, 1989.

33 O'REILLY, R. A. - Anticoagulant, antithrombotic, and thrombolytic drugs, in Gilman AG, Goodman LS, Rall TW, Murad F (eds): The Pharmacological Basis of Therapeutics. 7 ed. New York Macmillan, 1985, pp. 1338-1359.

34 PEARSON, P. J.; LIN, P. J.; EVORA, P. R. B.; SCHAFF, $H$. V. Endothelium-dependent response of the human internal mammary artery to hypoxia. No prelo. $A m$ J. Physiol., 1992.

35 PEARSON, P. J.; SCHAFF, H. V.; VANHOUTTE, P. M - Long-term impairment of endothelium-dependent relaxations to aggregating platelets following reperfusion injury in canine coronary arteries. Circulation, 81:1921-1927, 1990.

36 PROCACCINI, B.; CLEMENTI, G.; BERSANETTI. L.; MAZZOLA, A.; GREGORINI, R.; DI MANICI, G. P.; 
ÉVORA, P.R.B.; PEARSON, P.J.; SCHAFF, H.V. - Alguns aspectos da função endotelial em cirurgia cardiaca. Rev. Bras. Cir. Cardiovasc., 8(3): 195-214, 1993.

ESPOSITO, G.; DI NARDO, D. W.; DI EUOSANIO, G. - Cardiorespiratory effects of protamine sulfate in man: Intra-aortic vs intra-right atrial rapid administration after cardiopulmonary bypass. J. Cardiovasc. Surg., 28:112-119, 1987.

37 RADOMSKI, M. W.; PALMER, R. M. J.; MONCADA, S. - The anti-aggregating properties of vascular endothelium: interactions between prostacyclin and nitric oxide. Br. J. Pharmacol., 92:639-646, 1987.

REES, D. D.; PALMER. R. M. J.; HODSON, H. F.; MONCADA, S. - A specific inhibitor of nitric oxide formation from L-arginine attenuates endotheliumdependent relaxation. Br. J. Pharmacol., 96:418$424,1989$.

RUBANYI, G. M.; ROMERO, J. C.; VANHOUTTE, P. M. - Flow-induced release of endothelium-derived relaxing factor. Am. J. Physiol., 250 (Heart. Circ. Physiol. 19):H1145-H1149,1986

SALDANHA, C. \& HEARSE, D. J. - Coronary vascular responsiveness to 5 -hydroxytryptamine before and after infusion of hyperkalemic crystalloid cardioplegic solution in the rat heart. J. Thorac. Cardiovasc. Surg., 98:783-787, 1989

41 SHIMOKAWA, H.; FLAVAHAN, N. A.; VANHOUTTE, P.M. - Loss of endothelial pertussis toxin-sensitive $G$ protein function in atherosclerotic porcine coronary arteries. Circulation., 83:652-660,1991.

SHIMOKAWA, H.; FLAVAHAN, N. A.; VANHOUTTE, P. $M$. - Prostacyclin releases endo-thelium-derived relaxing factor and potentiates it's action in coronary arteries of the pig. Br. J. Pharmacol., 95:1197-1203, 1988.
43 SOLBERG, S.; LARSEN, T.; LINDAL, S.; PRYDZ, P.; JORGENSEN, L.; SORLIE, D. - The effects of two different crystalloid cardioplegic solutions on cultured human endothelial cells. J. Cardiovasc. Surg., 30:669-674, 1989.

44 STERNWEIS, P. C. \& GILMAN, A. G. - Aluminum; a requirement for activation of the regulatory subunit of adenylate cyclase by fluoride. Proc. Natl. Acad. Sci. (USA), 79:4888-4891, 1982.

45 VALLANCE, P.; COLLIER, J.; MONCADA, S. - Effects of endothelium-derived nitric oxide on peripheral arteriolar tone in man. Lancet, 2:997-1000, 1989.

46 WAKEFIELD, T. W.; HANTLER, C. B.; LINDBLAD, B; WHITEHOUSE, W. M.; STANLEY, J. C. - Protamine pretreatment attenuation of hemodynamic and hematologic effects of heparin-protamine interaction. J. Vasc. Surg., 3:885-889, 1986.

47 WAKEFIELD, T. W.; TILL, G. O.; LINBLAD, B.; SAENZ, N.; STANLEY, J. C. - Complement depletion and persistent hemodynamic-hematologic responses in protamine-heparin reactions. J. Surg. Res., 45:320$326,1988$.

48 WHITMAN, G. J. R.; MARTEL, D.; WEISS, M.; POCHANAPRING, A.; SEE, W. M.; HOPEMAN, A.; HARKEN, A. H.; DAUBER, I. M. - Reversal of protamineinduced catastrophic pulmonary vasoconstriction by prostaglandin $\mathrm{E}_{1}$. Ann. Thorac. Surg., 50:303-305, 1990.

49 YANG, Z.; VON, SEGESSER, L.; BAUER, E.; STULZ, P.; TURINA, M., LUSCHER, T. F. - Different activation of the endothelial L-arginine and cyclooxygenase pathway in the human internal mammary artery and saphenous vein. Circ. Res., 68:52-60, 1991. 